\title{
On the Variation, Races and Migrations of the Mackerel (Scomber scomber).
}

\author{
By
}

Walter Garstang, M.A., F.Z.S.,

Naturalist in charge of Fishery Investigations under the Marine Biological Association; late Fellow of Lincoln College, Oxford.

\section{INDEX OF CONTENTS.}

\begin{tabular}{|c|c|c|c|c|c|}
\hline & Introduction & & . & . & 235 \\
\hline I. & The Method of Investigation & & . & . & 238 \\
\hline II. & The Characters Investigated & & & . & 240 \\
\hline III. & Particulars concerning the Consi & gnments of & Mackerel Investig & igated & 40 \\
\hline IV. & Size of the Mackerel Investigated & & & & \\
\hline v. & Sex (Numerical proportions, Seco & ndary Sexua & ıal Characters) & . & 249 \\
\hline VI. & Number of Transverse Bars & . & . & & 3 \\
\hline VII. & Transverse Bars & & 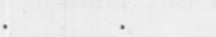 & & 261 \\
\hline VIII. & Dorso-lateral Intermediate Spots & & $\cdot$ & & 263 \\
\hline IX. & Number of Finrays in First Dors & al Fin & . & . & 267 \\
\hline $\mathrm{X}$. & Correlation between Spottiness an & ad Number o & of First Dorsal Fi & Pinray & . \\
\hline $\mathrm{XI}$. & Number of Finrays in Second Do & orsal Fin & 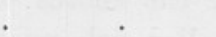 & . & 8 \\
\hline XII. & Number of Dorsal Finlets & & . & - & 280 \\
\hline XIII. & Correlation between Second & al $\mathrm{F}$ & Finle & & 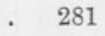 \\
\hline XIV. & F & g th & Mack & - & 284 \\
\hline $\mathrm{XV}$. & The Migrations of the Mackerel & & . & & 86 \\
\hline
\end{tabular}

Pour bien savoir les choses il en faut savoir le détail.

De la Rochefoucauld.

INTRODUCTION.

THE present investigation was undertaken at the invitation of H.M. Treasury, in consequence of an application to the government from H.M. Inspectors of Irish Fisheries for a scientific investigation into the life-history of the mackerel. The problem to the solution of which the inspectors attached particular importance was the relation to one another of the spring and autumn schools of mackerel which regularly visit the Irish coasts. In the spring a multitude of large fish approach the south and west coasts of Ireland to breed. In the autumn schools 
of immature, but usually well-grown, mackerel come around the island. According to one of the inspectors, the Rev. W. S. Green, there is a sharply defined interval between the two visitations of fish.

The first result of the Treasury's communication was the preparation by $\mathrm{Mr}$. Allen of a report on the "Present State of Knowledge with regard to the Habits and Migrations of the Mackerel," which was published in this Journal in the autumn of last year. (vol. v., No. 1, August, 1897, pp. 1-40.) This report contains a compendious and suggestive summary of all the reliable information we possess up to the present concerning the geographical and seasonal distribution of the mackerel, its rate of growth and breeding habits, and the extent and causes of its migrations.

It will readily be understood that the investigation of the relations between the spring and autumn fish of the Irish coasts could not profitably be undertaken except as part of a general scheme which should embrace the study of the mutual relations of the mackerel of neighbouring seas as well; for hitherto it has not been ascertained whether the Irish fish as a whole are peculiar to Irish waters, or whether there is any intermingling with the mackerel of the English Channel and North Sea. The general impression appears to be that the mackerel round all the British coasts form a single race or family, which becomes dispersed during the summer in order to occupy the various seas and channels round our islands, but becomes largely reunited in the winter after the autumn migrations. Upon this theory the separation of the mackerel family is determined principally by size, the larger fish remaining near the shores of the ocean, from the Irish coast to the Lizard, the smaller fish pushing their way northwards and eastwards into the shallower waters of the Irish Sea, the English Channel, and the North Sea. This view is expressed, for example, by Day in his British Fishes, and by Mr. Matthias Dunn (Report Royal Cornwall Polytechnic Soc., 1893). But the separation of the large Atlantic class from the small class found in the more enclosed waters is not regarded by these writers as in any way permanent. Every year, according to Mr. Dunn, the Atlantic (or Irish) class receives a reinforcement from the larger fish of the second (or shallow water) class; while the younger fish which have been bred off the Atlantic coast tend, in the spring of the year, to make common cause with the fish which frequent the English Channel. There is thus a complete mixture between the two classes, which cannot consequently be regarded as constituting local races in the sense in which we speak of Baltic and North Sea herring as forming separate races.

A still more decided view of the unity of the mackerel family has been entertained by Mr. W. S. Green, the energetic Inspector of Irish 
Fisheries, who points to the similarity of the mackerel on both sides of the Atlantic as evidence of probable intercommunication between the American and European representatives of the species (Bull. U.S. Fish. Com., xiii., 1893, p. 357), and the same view appears to have been held, though reservedly, by Mr. Dunn (loc. cit., p. 3 of reprint).

Clearly the first thing to be settled at the outset of the investigation was the relationship between the mackerel of different seas. In addition, therefore, to consignments of fish from Irish and English ports, I have endeavoured at different times to secure representative samples of foreign fish. Of American fish I examined a number during my visit, to Canada and the United States in the autumn of 1897 , both at Toronto and in the Fulton Market at New York, and the Association is indebted to the United States Fish Commission for the transmission, in October, 1897, of an excellent sample of one hundred fish from Newport, Rhode Island. To Mr. W. de C. Ravenel, Acting Commissioner at that time, I desire to express my thanks, on behalf of the Association, for his kind and courteous assistance in the matter. To the Directors of the Hamburg-American Line we are also under a debt of gratitude for their gratuitous conveyance of this box of fish in a refrigerator of one of their express steamers direct from New York to Plymouth, an arrangement which contributed largely to the excellent condition of the fish on arrival after their long journey. From Brest I received a consignment of one hundred fish, for which, as for many other services, I have to thank Mr. W. S. Hoare, the British Consul at that port. Capt. W. Arthur, of the s.s. Gipsy, who had rendered me much assistance on an earlier occasion, by placing his boat at my disposal for securing some temperature and other observations, kindly conveyed the box of fish direct to Plymouth. I have also much pleasure in thanking Prof. Marion, of Marseilles, for a sample of Mediterranean fish, though they arrived too late to enable me to incorporate the results of their examination in the present report. Unfortunately, a consignment of fish which I expected from Norway has not arrived, and I must postpone until next spring any comparison between the British fish and those which annually visit the Scandinavian coast.

The sources of the English and Irish fish examined are given in the tables, and in the list of particulars concerning the consignments. It will suffice to say that I have received samples of several hundred fish from each of the following regions: the West and South coasts of Ireland, the English Channel, and the North Sea. Altogether I have examined in detail some 1800 fish, and the total number included in the tables of variation appended to this report amounts to 1649 . The omission of about 150 fish from the tables is due to the fact that about 100 Plymouth fish were used in a preliminary enquiry before the general 
plan of investigation was decided upon, and that a number of fish caught at Plymouth during the summer of 1897 were so much smaller than any from other localities (from 4 to 9 inches in length), that I have thought it better to reserve most of the results of their examination until a sufficient number of young forms has been also obtained from other parts. These small fish are frequently taken in sprat seines, weirs, and in other ways on various parts of the British coast, and I should be much obliged to any who read these lines, and have the opportunity of assisting, if they would kindly forward to me any specimens of the common mackerel they may come across below 8 inches in length. They should be forwarded fresh (but damp) by post, if in small quantity; or in seaweed or ice by train, if in quantity; and the locality, date, and method of capture should be recorded. The cost of carriage, \&c., will be willingly paid by the Association.

As regards the condition of the fish in the different consignments under examination, I should say that the Plymouth fish have been examined in a perfectly fresh condition, but that all other fish, except those in two Irish consignments, have been iced before examination, in order to enable them to withstand the effects of a more or less lengthy journey by rail or sea. The two Irish consignments referred to were those dated Kinsale, July 30th and September 3rd, 1897. These fish arrived during my absence in Canada, and after measurement were placed in tanks of formaline to await my return. With this exception, the condition of the different consignments at the time of examination may be regarded as practically uniform, so far as external characters are concerned. The viscera of the fish from Brest, and of some of the earlier Irish samples were, however, so rotten, owing to delays in transit, that no attempt was made to record the sexual condition of all the fish in these particular samples.

After this introduction I may proceed at once to describe the methods and results of the investigation up to the present time.

\section{The Method of Investign 3 ion.}

As all attempts to discover constant individual peculiarities in the mackerel of any one locality, as compared with those from any other, have completely failed, it is clear that, in order to determine whether local races exist or not, recourse must be had to the detailed study of the variation of certain chosen characters in the fish of different localities. The range of variation in these different local groups of fish can then be compared, and the frequency with which particular variations, or combinations of variations, occur in any one group can be compared with its frequency in all the others. Thus, if we suppose 
the number of finrays in the first dorsal fin to vary between 10 and 14, the value 12 will probably occur with greatest frequency. But other possibilities occur; and while 12 might be constantly the most frequent value in samples of one local group of fish, it is quite conceivable that 13 might be constantly the most frequent value in samples of another group; in which case, if the two groups were examined under similar conditions of sex, size, preservation, and so forth, we should be prepared to regard the two groups as racially distinct, the one indispensable condition being that the frequency of the particular variation shall have been determined in all instances upon a sufficient number of specimens.

It is, however, impossible to assign any one number beforehand as universally sufficient. The minimum sufficient number may be regarded as that which yields results approximately coinciding with those derived from an infinitely large number, i.e., the percentages of frequency derived from it must bear some close degree of correspondence with the percentages derived from a much larger number. I have taken 100 as the minimum number of mackerel from which it is possible to derive a fairly reliable statement concerning the relative frequency of the variations exhibited by any one of the chosen characters. But the number of specimens requisite to yield a reliable statement of the frequency of variations of any organ bears a relation to the variability of the organ. If an organ varies slightly, the number of specimens must be increased. It is certain, for example, that 100 is an inadequate number for determining the normal frequency of the variations in the number of the dorsal finlets in the mackerel of British seas (see table H, p. 295); for, among 100 fish from Ramsgate, not a single specimen possessed less than 5 finlets, and 5 specimens possessed more than that number; whereas, of 300 fish from Lowestoft, $1 \%$ possessed only 4 finlets, and only $3 \%$ possessed 6 ; and of 300 Plymouth fish, the percentage (3) of specimens with the lower number was almost as great as the percentage (4) of those with the higher. On the other hand, the number (100) is quite sufficient to show a marked difference between the American and the British fish in regard to the same character, since nearly $20 \%$ of the American fish possessed 6 finlets-a percentage almost four times as great as that observed in any other sample of $100 \mathrm{fish}$.

In order to check the adequacy of this number as a unit-sample for determining the frequency of the variations of more variable characters, we may turn to table B (p. 290), which deals with the variation in number of the black stripes or bars across the sides of the fish. We see there that in each sample of 100 fish from Lowestoft, Ramsgate, and Plymouth, the frequency of the values above 27 is constantly less than 
that of values below 27; whereas for each sample of about* 100 fish from Ireland, the values above 27 are, with only one exception, in excess of the values below that number. The constancy of this relation for each of the geographical areas mentioned appears to me to show that 100 is very nearly a sufficient sample, in the sense already defined, so far as this character is concerned.

As a matter of fact, the four important regions for mackerel fisheries round our coasts, viz., the North Sea, the Channel, the South and West coasts of Ireland, are each represented by a totality of fish of not less than 300 ; but I have entered at some length into this question, because I think that the division of the local groups into unit-samples provides a valuable means of checking the significance which may be attributed to the differences as determined for the local groups en masse.

\section{The Characters Investigated.}

After a preliminary study of the question, it seemed desirable to select numerical rather than dimensional characters for investigation, their variations being less dependent than those of the latter upon variable factors, such as disproportionate growth, food-supply, and enlargement of the reproductive organs. The characters eventually selected were the following:-

1. The Number of black Transverse Bars or Stripes across the sides of the fish, beginning at the point where the lateral line meets the posterior border of the scapular arch, and ending just behind the last dorsal finlet.

2. The Number of the same Transverse Bars which meet or cross the lateral line.

3. The Number of round black Dorso-lateral Intermediate Spots situated between the Transverse Bars.

4. The Number of Finrays in the First Dorsal Fin.

5. The Number of Finrays in the Second Dorsal Fin.

6. The Number of Dorsal Finlets.

The condition of each fish in regard to these six characters was recorded from the commencement of the investigation, in addition to the length of the fish, and, in the majority of cases, its sex. But I soon began to take note of other characters, in the hope of finding them useful in the end, and among these were the following :-

7. The general Shape and Regularity of Arrangement of the Trans-

* The irregularity in the number of fish in the samples from Ireland was due, I understand, to a curious system of depredation during transit which prevails in those parts, and is sanctioned by custom or, at least, endurance. 
verse Bars, i.e., whether straight, > shaped, or wavy; and whether regular, fairly regular, rather regular, or irregular.

8. The Continuity or Degree of Discontinuity of the black longitudinal Streak which is present in most mature fishes below the lateral line. I call this character the "Lateral Streak."

9. The extent and character of the Dusky Markings which are frequently found in mature fishes below the Lateral Streak, especially in the anterior half or third of the body length. These markings, when well developed, have the form of a fine zigzag tracery, but they are often diffuse and blurred. I call this character the "Sublateral Tracery."

10. The Abundance and Distribution of small irregular dusky Spots, frequently found on the posterior part of the abdominal region, and scattered over and among the Transverse Bars of the Dorsolateral Area. They are to be sharply distinguished from the round black Spots which I have termed "Dorsolateral Intermediate Spots." The pigment of these latter is a deep black, and it is situated at a lower level in the tissues than the pigment of the irregular "Dusky Spots." Moreover, the Dorsolateral Spots are invariably situated between two adjacent Transverse Bars, of which, in a morphological sense, they are undoubtedly discontinuous modifications. The Dorsolateral Spots are independent of the growth of the fish, being as frequent in small fish as in large, but the "Dusky Spots" appear to make their first appearance about the time of maturity.

11. The Extent of a black longitudinal Connecting Streak which connects the ventral ends of the Transverse Bars. The Connecting Streak is usually confined to the posterior quarter or third of the body-length, but occasionally extends further forwards, and in rare instances traverses the whole length of the body, intersecting the lateral line at an acute angle. In such cases the "Lateral Streak" is frequently ill-developed.

Of these accessory characters, only the first (No. 7-the Shape of the Transverse Bars) has been considered in the present report, owing to its suggested bearings on the question of secondary sexual peculiarities.

The data acquired in regard to the variation of the remaining accessory characters are not discussed in the present report, although I hope to make use of them on a future occasion. My reasons for omitting them are chiefly that some of the characters (Nos. 8, 9, and apparently 10) were found to arise rather late in life, about the time of maturity; and as the exact size at which they make their appearance is itself subject to variations, it was considered inadvisable to introduce such characters into a discussion of racial peculiarities until the causes which determine their appearance have been more definitely ascertained. 
These three characters, in fact, depend upon a formation of pigment in the superficial layers of the skin, apparently different in kind from that which brings about the transverse bars and intermediate spots. Some further study of the pigmentation of the mackerel will be necessary before their value for racial determinations can be assured. This objection does not apply, it is true, to the last character enumerated (No. 11); but my records of the variation of this character were commenced much later than those of all the others, and are not yet sufficient to yield any general results.

The investigation in hand accordingly rests upon an examination of the variation of seven characters, of which six are numerical and one morphographical. Four of these characters deal with the characteristic markings of the fish, and three with the structure of the dorsal fins.

It will be noticed that the number of transverse bars has been recorded twice for each fish; firstly, as an entire series, and secondly, between certain arbitrary limits. This has been done with a view to expose any errors which might arise from the fact that the bars are not always distinct and parallel, but are frequently branched and anastomosed with one another, broken, or otherwise irregular, rendering the task of enumeration not always easy, and so introducing a certain subjective element into the records. Now the number of bars, or portions of bars, which cross or meet the lateral line admits of fairly exact enumeration, and seemed to me to offer an excellent method of checking the estimate formed of the number of bars in the entire series. In this expectation I have not been disappointed, as the discussion of tables $\mathrm{B}$ and $\mathrm{C}$ will reveal, although the fact that the course of the lateral line itself is also subject to slight variations has naturally prevented an absolute correspondence in all details between the two modes of enumeration.

It only remains to add that the number of transverse bars and of intermediate spots, together with the data concerning the shape of the bars, have all been determined upon the same side of the fish, viz., the left. I frequently took note of the condition of the right side of the fish also, but these notes are nowhere referred to in the present report, and are not incorporated in any of the tables.

\section{Particulars Concerning the Consignments of Mackerel INVESTIGATED.}

In this section are given the place, date, and method of capture, the name of the consignor, and such other information as may bear upon the authenticity and representative character of the samples. All the samples were forwarded to Plymouth in ice, except those which were 
caught in the neighbourhood of that port. The samples are enumerated in the order in which they appear in the tables at the end of this report. The order is geographical, except that the American sample, the characters of which are shown to be quite peculiar, is placed at the head of the list.

NewPoRt, U.S.A., October 18th, 1897. 100 fish. "The mackerel are just as they were taken from the water, without selecting as to sizes, but being a perfect sample of a catch of 400 fish taken in a trap or pound net in the waters near Newport, R.I."-Messrs. Blackford, of Fulton Market, New York. (See Introduction.)

Lowestoft (1.) October 7th, 1897. 100 fish. Caught in nets 4 miles S.E. from Lowestoft. "These are the finest sample of fish to-day for the season. They have been much smaller hitherto. They are not selected."-Mr. Alfred T. Turner, Trawl Market, Lowestoft.

(2.) October 12th, 1897. 50 fish. Caught in nets 14 miles S. by E. from Lowestoft-Mr. Turner. These are the half of an average 100 of fish taken direct from the boat; but they are not representative of the whole catch, as, owing to a misunderstanding, the 50 smaller fish out of the hundred were alone forwarded. "The difference in size between the two half-hundreds was, however, not great."-A. T. T.

(3.) June 28th, 1898. 50 fish. Nets. A representative sample from Mr. Turner.

(4.) July 12th, 1898. 100 fish. Caught in nets 10 or 12 miles E. of Lowestoft, "quite abreast of the town."-Mr. Turner. A representative sample, except that the four smallest fish (measuring $11 \frac{1}{2}$ and $11 \frac{3}{4}$ inches in length), out of a total of 104 examined, have been eliminated.

Ramsgate, October 27th, 1897. 100 fish. Caught in nets off the Kentish Knock, about 20 to 24 miles from Ramsgate Harbour. A representative sample. Messrs. W. Ferridge \& Co., Central Fish Market, Ramsgate.

Plymouth (1.) July to October, 1897. 76 fish. Caught in a variety of ways. Not representative. The following are the dates, places, and methods of capture.

July 21st. In the Sound near the Laboratory. Seine. 12 fish.

„22nd. 1 mile S. of Breakwater. Hook and line. 13 fish.

Sept. 21st. Probably off Penlee Point. Hook. 10 fish.

" " River Tamar, 5 miles above Saltash. 1 fish.

Oct. 7th. River Tamar, Saltash to Cargreen. Small-meshed drift net. 3 fish.

"20th. Between Eddystone and Mewstone. Pilchard nets. 19.

"27th. Probably off Eddystone. Pilchard nets. 18 fish. 
(1b.) September to November, 1897 . This modification of the preceding sample occurs in table D. It consists in the substitution of 25 small November fish, caught principally in herring nets, for the 25 fish caught in July. It was required owing to the fact that the character to which table D refers was not examined in any British fish before my visit to America in August.

(2.) Nov. 16 th to 20 th, 1897.100 fish. Caught on the 16 th, 17 th, 18th, 19th, and 20th November, in drift nets worked a few miles S.E. from the Eddystone (14-18 miles S. of Plymouth Breakwater). Supplied by Mr. J. Turner, Plymouth. The sample is not quite representative. The total number examined was 109 , but the nine smallest (from $10 \frac{1}{4}$ to $11 \frac{3}{4}$ inches in length) were eliminated.

At this time enormous numbers of drift mackerel were being taken in this locality, especially on the nights of the 16th and 17th November. Smaller fish, from $7 \frac{3}{4}$ to 11 inches in length, were commonly taken at the same time in herring nets worked nearer shore.

(3.) July 6th, 1898. 100 fish. Caught in nets 30 miles south of the harbour. Supplied by Mr. Turner. Not quite representative. The total number examined was 118, but the 18 smallest (from 10 to 11 inches in length) have been eliminated.

(4.) July 11th, 1898. 24 fish. Caught at mid-day in the Sound, immediately below the Laboratory, in a seine. The sample is fairly representative of the total catch of $600 \mathrm{fish}$.

ScILly (1.) May 8th, 1898. 12 fish. Caught off Bishop Lighthouse, May 7 th and 8 th. Landed at Plymouth, May 9 th.

(2.) June 2nd, 1898. 12 fish. Caught "in light green water" 80 to 90 miles S.W. by W. (magnetic) from Newlyn, i.e., about 65 miles S.S.W. (true) from St. Mary's, Scilly. Total catch, 600. Forwarded by Mr. B. J. Ridge of Newlyn, Penzance. ["Fish caught off the Bishop Lighthouse about this time were mostly shotten.”-B. J. R.]

(3.) June 9 th, 1898. 50 fish. Caught 20 miles S.W. from the Wolf Lighthouse. Forwarded by Mr. B. J. Ridge.

BREst, June 20th, 1898. 100 fish. Caught by hook and line off Camaret, south of Brest, France, and forwarded in ice by steamer direct from Brest to Plymouth. (See Introduction.) The length of one fish was not recorded, but is assumed to have been 14 inches, the most frequent size.

Kinsale (1.) July 30th, 1897. 119 fish. Caught with nets off the Old Head of Kinsale. Forwarded by Mr. James Carroll, Fish Merchant, Kinsale, per Cork steamer to Plymouth. Note from sender:- "They are a fair average specimen of the fish now being taken. All mackerel now captured are of small size and poor quality- 
will much improve about September." Placed in formaline on arrival at the Laboratory, and examined Sept. 19th, 24th, and 25th.

(2.) Sept. 3rd, 1897. 99 fish. Caught with nets off the Old Head of Kinsale. "A fair average specimen of the fish now being taken." Forwarded by Mr. Carroll. Placed in formaline on arrival at the Laboratory, and examined Sept. 16th to 19th.

(3.) Sept. 17th, 1897. 92 fish. Caught with nets off the Old Head of Kinsale. "A fair average specimen of the fish now being taken." Mr. Carroll.

(4.) July 1st, 1898.100 fish. Mr. Carroll.

SMeRwick, March 12th, 1898. 99 fish from Smerwick Harbour, County Kerry; forwarded by Mr. John McKenna, Butter Merchant, Dingle.

Brandon (1), April 16th, 1898. 45 fish. Caught at Brandon Creek, County Kerry; forwarded by Mr. McKenna. 46 fish actually arrived, but the smallest (length, $12 \frac{1}{4}$ inches) has been eliminated, owing to its marked divergence in size from the rest of the sample.

(2.) April 23rd, 1898. 101 fish. Caught at Brandon Creek; forwarded by Mr. McKenna.

\section{Size of the Mackerel Investigated.}

The length of the body has been taken as the basis for comparing the relative sizes of the fish investigated, and this has been measured in all cases from the tip of the closed jaws to the median extremity of the fork of the tail. The longer rays of the tail-fin are subject to accidents in capture and transit, and cannot therefore be included in an accurate comparative table of measurements; but it should be remembered that these rays are generally included in ordinary measurements of body-length, which would consequently be somewhat in excess of my determinations. The fish have always been measured in the same way, by placing them with their left sides uppermost upon a measuringboard, with the tip of the jaws touching a vertical plate immoveably fixed at the zero of the scale, which is accurately ruled to quarters of an inch. The length of the fish has been read off to the nearest quarter.

The observed number of specimens of the different sizes represented in each consignment of fish is recorded in table A. The general size of the fish representing each locality can, however, be more readily gathered from the more condensed statements given below, which are in percentages of the total number from each locality. In Table I. the size is indicated in inches, the fractional differences recorded in table A 
being neglected. In Table II., which is still further condensed, the range of size included in each vertical column is 2 inches.

TABLE I., showing Distribution of Size in One-inch Groups. (Percentages.)

\begin{tabular}{|c|c|c|c|c|c|c|c|c|c|c|c|}
\hline \multirow{2}{*}{\multicolumn{3}{|c|}{ Place of Capture. }} & \multirow{2}{*}{$\begin{array}{l}\text { No. of } \\
\text { Fish. }\end{array}$} & \multicolumn{8}{|c|}{ Length of Fish (inches). } \\
\hline & & & & $10+$ & $11+$ & $12+$ & $13+$ & $14+$ & $15+$ & $16+$ & $17+$ \\
\hline Newport, & .S.A. & . & 100 & \multirow{5}{*}{5} & $2 \%$ & $53 \%$ & $33 \%$ & $10 \%$ & $1 \%$ & \multicolumn{2}{|l|}{$1 \%$} \\
\hline Lowestoft & . & . & 300 & & 3 & 28 & 48 & 20 & 1 & & \\
\hline Ramsgate & . & . & 100 & & 4 & 23 & 40 & 25 & 5 & \multicolumn{2}{|l|}{3} \\
\hline Plymouth & . & . & 300 & & 29 & 38 & 21 & 5 & 2 & & \\
\hline Scilly . & . & . & 74 & & 5 & 33 & 27 & 22 & 8 & 4 & 1 \\
\hline Brest & . & . & 100 & \multirow{3}{*}{$\frac{1}{2}$} & 1 & 2 & 36 & 42 & 14 & \multirow[t]{2}{*}{4} & \multirow[t]{2}{*}{1} \\
\hline Kinsale . & . & . & 410 & & 23 & 55 & 15 & 5 & 1 & & \\
\hline Kerry . & . & . & 245 & & & 7 & 20 & 33 & 29 & 11 & $\frac{1}{4}$ \\
\hline Irish: $\mathrm{Au}$ & umn & . & 310 & \multirow[t]{2}{*}{$\frac{1}{3}$} & 30 & 63 & 7 & & & & \\
\hline Irish: Spr & & - & 345 & & $1 \frac{1}{2}$ & 14 & 25 & 30 & 21 & 8 & $\frac{1}{4}$ \\
\hline
\end{tabular}

TABLE II., showing Distribution of Size in Two-inch Groups. (Percentages.)

\begin{tabular}{|c|c|c|c|c|c|c|c|}
\hline \multirow{2}{*}{\multicolumn{3}{|c|}{ Place of Capture. }} & \multirow{2}{*}{$\begin{array}{l}\text { No. of } \\
\text { Fish. }\end{array}$} & \multicolumn{4}{|c|}{ Length of Fish (Inches). } \\
\hline & & & & $10+11$ & $12+13$ & $14+15$ & $16+17$ \\
\hline Newport & . & . & 100 & 2 & 86 & 11 & 1 \\
\hline Lowestoft & . & . & 300 & 3 & 76 & 21 & \\
\hline Ramsgate & . & . & 100 & 4 & 63 & 30 & 3 \\
\hline Plymouth & . & . & 300 & 34 & 59 & 7 & \\
\hline Scilly . & . & . & 74 & 5 & 60 & 30 & 5 \\
\hline Brest . & . & . & 100 & 1 & 38 & 56 & 5 \\
\hline Kinsale. & . & . & 410 & 24 & 70 & 6 & \\
\hline Kerry . & . & . & 245 & & 27 & 62 & 11 \\
\hline Irish : Aut & amn & . & 310 & 30 & 70 & & \\
\hline Irish: Spri & & . & 345 & 2 & 39 & 51 & 8 \\
\hline
\end{tabular}

These tables show that the great majority of fish investigated were from 12 to $13 \frac{3}{4}$ inches in length.

The Lowestoft and Ramsgate samples closely resemble one another in size, the latter having a slight preponderance of the larger fish.

The samples of smallest-sized fish were those from Plymouth and Kinsale, and these may be regarded as practically similar to one another in this respect. They show a considerable percentage $\left(24 \%\right.$ to $34^{\circ} \%$ ) of fish below 12 inches in length, a percentage much higher than that in any other of the local samples. The percentage of fish above $13 \frac{3}{4}$ inches in length is also excessively small in these two samples, being 
only $6 \%$ or $7 \%$, whereas it is $21 \%$ for Lowestoft, $30 \%$ for Ramsgate, and about $60 \%$ for Brest and County Kerry.

The samples of largest-sized fish are those from Brest and County Kerry, in which there are practically no fish below 13 inches in length.

The American fish are intermediate in character between the Lowestoft and Plymouth samples, but are unique in regard to their great uniformity in size, $86 \%$ being between 12 and $13 \frac{3}{4}$ inches in length.

The fish in the Scilly sample are a mixed lot, obtained over a wide area at the western entrance to the English Channel. As the total number of these fish does not amount to the number already assigned as the minimum for a unit sample, their variations are not much discussed on the present occasion; but it is interesting to notice the curious distribution of sizes among these 74 fish which were all captured within a single month. The sample shows three distinct maxima of frequency, one at 12 inches, another at 13 inches, and another at 14 inches (see table A). This phenomenon is not due solely to the mixture of samples from different localities, for it is shown also in the single consignment of 50 fish captured on June 9 th.

From what has been said, it will be seen to be possible to divide the local samples into groups characterised by the preponderance of large, moderate, or small sized fish. This grouping takes the following form :-

$\begin{array}{ll}\text { Large : } & \text { Kerry. } \\ & \text { Brest. } \\ \text { Moderate : } & \text { Lowestoft. } \\ & \text { Ramsgate. } \\ & \text { Scilly. } \\ & \text { Newport, U.S.A. } \\ \text { Small : } \quad \text { Plymouth. } & \text { Kinsale. }\end{array}$

This grouping is by no means to be understood as implying that the mackerel found in these localities constantly bear the size relations assigned to them here. It is no doubt true that the largest fish are always most abundant on the Atlantic coast, but the correspondence between the samples and the natural distribution of the fish in this instance must be regarded as an exceptional coincidence. The samples are only representative of the fish caught at the dates mentioned in the tables (subject to certain reservations already given in the particulars concerning the consignments). To draw general conclusions upon the natural distribution of size among the fish all round our coasts, it would be necessary to secure the regular delivery of representative samples from fixed stations throughout the year, as was done, for example, by the Scottish Fishery Board in the case of the herring (4th Report S.F.B., 
1886, pp. 65-72). Such an arrangement would be decisive, but expensive, and could not, I believe, be undertaken by the Association under present conditions. An attempt which I made in the Autumn of 1897 to secure the periodic consignment of a small sample from Kinsale fell through owing to the refusal of the fish merchant to undertake the supply of small quantities, the price of which would not repay him for his trouble.

Nevertheless, in spite of their incompleteness, the following general features of the samples may be advantageously summarised, if only as a means of inviting further attention to the subject:-

1. Large fish, measuring 14 inches and upwards, preponderate only on the Atlantic coasts of Ireland and Brittany. The sample from Brest is particularly valuable as an index of distribution, because the fish composing it were all caught with hook and line, the sizes in most of the other samples being partially determined by the mesh of the nets with which the fish were captured. The late date (June 20th) at which these large Brest fish were taken close to shore is also worthy of notice. The sample caught at Kinsale some ten days later (July 1st) consisted of distinctly smaller fish.

2. On the Irish coast the spring fish are much larger than the autumn fish; but in the Channel and North Sea no such difference is to be recognised. Indeed, in the latter areas the autumn fish appear on the whole to be slightly larger than the early breeding fish, and seem to be the same fish at a later stage of growth.

3. The sequence of events on the Irish coast, as indicated by table A, appears to be as follows: In March* moderately large fish (13 and 14 inches) arrive; in April the size of the fish attains its maximum (a preponderance of 14 and 15 inch fish); at the end of June (Kinsale, July 1st) the proportion of large fish is greatly reduced, and there is a considerable accession of small fish (11 and 12 inches), the total range of size being now at its maximum; by the end of July the large fish have all disappeared, and there is a preponderance of 11 inch fish; and from now onwards the size gradually but slightly increases, as though by growth rather than by new immigrations of larger fish. In this summary I have assumed that samples of fish caught off the South and West coasts of Ireland (i.e., Kinsale and Kerry) are equally representative of the general size prevailing at the periods of capture, though I have no doubt that the examination of simultaneous samples from the two coasts will reveal slight differences, at any rate, in this respect. This point I hope to elucidate during the present autumn and the next spring seasons.

* Two large mackerel, one of each sex, were forwarded to me by Mr. Green in February. They measured 16 ins, in length, and were caught off Gariness, Co. Cork, on Feb. 23rd, 1898. 


\section{SeX.}

$\S 1$. Proportion of the Sexes. Out of a total of 918 mackerel caught in British waters 423 were males and 495 females, forming a percentage of 46 males to 54 females, or a proportion of 117 females to every 100 males.

This excess of females over males is slight compared with the preponderance of this sex which Fulton has shown to exist in the case of most sea-fishes with pelagic eggs. (8th Report Scottish Fishery Board, 1890 , p. 349 ; 9th Report, 1891 , p. 247 . Partially quoted in Cunningham's "Marketable Fishes," 1896, p. 76.) In this respect the mackerel comes nearest to the cod, in which the proportion of females to 100 males is 133 .

The explanation which Fulton suggests of the general preponderance of females in species of sea-fishes is founded on the great difference in bulk between the ripe ovary and testis, which often leads to obvious differences in the degree of distension of the abdominal cavity in the two sexes during the breeding season. The necessity for the annual production of a certain minimum number of eggs, coupled with the difficulty experienced by the females of many species in carrying their proper quantity of ova, has accordingly led in some cases to a relative increase in the size of the females, in others to an increase in their relative number, or even, as indeed is generally the case, to an increase of the females under both these heads. The duration of the spawning season is also affected by the same factors.

As the general size of the female mackerel is shown in a subsequent section to be only slightly in excess of that of the male, we are probably correct in attributing the relatively slight preponderance of females in the mackerel to the relatively large body-cavity which this species possesses, as compared with the body-cavity of a gadoid or flatfish. The small size of the mackerel's egg also obviates the necessity for a large preponderance of females.

The large size of the body-cavity in the mackerel is probably, in its turn, connected with the active pelagic habits of this fish, as it would be a manifest impediment to vigorous movements if the abdominal region should become so distended in the spawning season as it is in the more lethargic cod and flatfish tribes. As the same feature is also found in the herring and pilchard, it would appear to be a general phenomenon among pelagic and so-called "migratory" species.

$\S 2$. Segregation of the Sexes. It has been maintained by Couch (British Fishes, vol. ii., p. 68) that the sexes of the mackerel become much divided during the early migration. Out of 20 specimens taken indiscriminately on one occasion during March he counted 16 males 
and only 4 females. During another season he counted 17 males to 3 females. It is true that on a third occasion Couch found the sexes to be equally represented in a sample of the earliest spring fish; but he explains this exception by adopting the opinion of the fishermen that the fish of this particular school belonged to a different class from the ordinary spring fish-that they were old fish of the preceding season which had not moved out into deep water, and that they did not represent the usual spring immigrants from the Atlantic.

The evidence of American observers on this point is conflicting (Commissioner's Report for 1881, U.S. Fish Com., 1884, p. 114).

My own observations on the proportion of the sexes in various samples of mackerel at different seasons are recorded in table E (p. 293). The only sample examined during March was one from Smerwick, County Kerry, and it certainly supports Couch's statements that in this particular sample the males were nearly twice as numerous as the females, 63 out of a total of 99 fish being of the former sex.

But it must be pointed out at the same time that an actual excess of males over females in particular samples is also found at other seasons of the year. Thus, out of 25 Lowestoft fish, captured October 12th, 1897, there were 15 males to 10 females; and out of 100 Ramsgate fish caught a fortnight later 55 were males. In the American sample, also caught during October, $55 \%$ were males. The preponderance of males in these cases is certainly not so great as in the Smerwick sample, but it is sufficient to show the necessity of caution in accepting conclusions of this kind based upon relatively small samples. Until observations on the subject shall have been considerably multiplied, I think it will be best to suspend judgment upon a matter which may be, biologically, of considerable importance.

In this connexion I would draw attention to the evidence submitted in the succeeding section, which shows that the numerical proportion of the sexes differs, as a whole, according to the size of fish under consideration, owing to a difference in the rate and limits of growth of the two sexes. Now it is an open question whether the so-called "schools" of mackerel are formed by the chance association of fish which happen to be near one another, independently of sex and size, or whether they are not due to the selective association of fish having some common characteristic. The evidence derived from samples of fish caught in drift-nets is of little value, owing to the selective action of the mesh of the nets. The evidence from samples caught in small-meshed seines would be fairly conclusive, but the existing data are too few to be of any use. Nevertheless, such evidence as we possess in the case of other fishes tends to show that selective association plays a considerable part in the formation of shoals, and that similarity of size is one 
of the points selected. Bateson, for example, speaking of the grey mullet, says, "Similarity in size seems to be usual in these shoals." (Journal M.B.A., I., p. 250.) If, therefore, we assume this principle in the case of mackerel shoals, it is clear, from the facts to be adduced shortly, that the normal preponderance of females will tend to be reduced in the case of shoals of fish below 14 inches in length, and increased in the case of shoals of fish measuring 15 inches or more, quite independently of any selective segregation of the sexes.

It is then possibly not without significance that, so far as my own samples go, a preponderance of males was only observed in samples of relatively small fish, more than half the fishes in each sample being below 14 inches in length, and a very small number (from $0 \%$ to $11 \%$ ) attaining a length of 15 inches.

§3. Sex and Size. The following table shows the observed frequency of male and female fish of the various sizes mentioned, in a total population of 918 mackerel, and also the same facts as percentages of this latter sum. This population consists of all the samples of British fish in which the sex has been determined, as shown in Table E. The American sample has been excluded, since the present investigation clearly shows the American fish to constitute a distinct race, much more remotely allied to the European fish than are the British races inter se. The last horizontal row of figures shows the relative number of females of each size compared with the number of males of the same size taken as 100 .

TABLE III., showing relation between Sex and Size.

\begin{tabular}{|c|c|c|c|c|c|c|c|c|c|c|}
\hline Length (Inches). & & $10+$ & $11+$ & $12+$ & $13+$ & $14+$ & $15+$ & $16+1$ & $17+$ & Total. \\
\hline Frequency observed. & $\begin{array}{l}\sigma \\
\uparrow\end{array}$ & $\begin{array}{l}1 \\
2\end{array}$ & $\begin{array}{l}37 \\
37\end{array}$ & $\begin{array}{l}114 \\
141\end{array}$ & $\begin{array}{l}140 \\
133\end{array}$ & $\begin{array}{c}86 \\
100\end{array}$ & $\begin{array}{l}36 \\
56\end{array}$ & $\begin{array}{c}8 \\
23\end{array}$ & $\begin{array}{l}1 \\
3\end{array}$ & $\begin{array}{l}423 \\
495\end{array}$ \\
\hline $\begin{array}{l}\text { Frequency in percentages } \\
\text { of the total number } \\
\quad=918 .\end{array}$ & $\begin{array}{l}\sigma \\
\wp\end{array}$ & $\begin{array}{l}0 \cdot 1 \\
0 \cdot 2\end{array}$ & $\begin{array}{l}4 \\
4\end{array}$ & $\begin{array}{l}12 \\
15\end{array}$ & $\begin{array}{l}15 \\
14\end{array}$ & $\begin{array}{c}9 \\
11\end{array}$ & $\begin{array}{l}4 \\
6\end{array}$ & $\begin{array}{c}1 \\
2.5\end{array}$ & $\begin{array}{l}0 \cdot 1 \\
0.3\end{array}$ & $\begin{array}{l}46 \% \\
54 \%\end{array}$ \\
\hline $\begin{array}{l}\text { Number of } q \text { compared } \\
\text { with } \delta \text { taken as } 100 .\end{array}$ & & - & 100 & 124 & 95 & 116 & 156 & 288 & 300 & $\begin{array}{c}117 \\
\text { (mean.) }\end{array}$ \\
\hline
\end{tabular}

The table shows that the females in my samples exceed the males in number at almost every size, the exceptions being at 11 inches where the frequency of males and females is the same, and at 13 inches where the males exceed the females by $1 \%$ of the total number. It is to 
be noticed that the males are relatively more numerous among the small fish than among the large; or, in other words, that the numerical ratio of males to females becomes more and more reduced as the size of the fish under consideration increases. This fact is expressed by the figures on the last horizontal line, which gives the number of females of each size corresponding to a constant number of males, taken as 100 . It will be seen that, except for a slight irregularity in the columns representing 12 and 13 inches, the relative number of females becomes considerably increased as the size enlarges.

As, however, the extreme sizes, both small and large, are represented by relatively small numbers of fish, whether male or female, a more reliable result will be obtained by dividing the fish into a smaller number of size-groups. Thus, in two-inch groups, the proportion of females to every 100 males becomes-

\begin{tabular}{|c|c|}
\hline \multicolumn{2}{|c|}{$10-11$ inches } \\
\hline $12-13$ & $"$ \\
\hline $14-15$ & " \\
\hline $16-17$ & $"$ \\
\hline
\end{tabular}

thus revealing an increase in the preponderance of females at every successive grade. The increase is not quite regular, being slight from 10 to 13 inches, then rapid at 14 and 15 inches, and very highly marked above 15 inches.

Two explanations of this increasing preponderance of females with increasing size suggest themselves :-

1. The males may be subject to a more rapid death-rate than the females; or

2. The growth of the males may be arrested at an earlier stage than that of the females.

As the true proportion of the sexes of the mackerel at the time of hatching or in ovo cannot be ascertained with our present knowledge, it is difficult to test the former alternative, which is a priori improbable, owing to the absence of any known differences between male and female mackerel as regards habits of life or structure of the body. So far as the physiological wear and tear of reproduction goes, this probably affects the female more severely than the male.

The second alternative is the more probable one, since sexual dimorphism in regard to size is a very common phenomenon, and in fishes the female frequently exceeds the male in length. Still the cessation of growth in the males does not take place uniformly at any one stage, since the extreme limit (17 inches) attained by the females in my samples is also attained by the males. The exact stage of cessation is clearly subject to considerable variation, and is probably 
preceded by a retardation in the relative rate of growth, as compared with that of females of the same size. It is improbable that any considerable percentage of males actually stop growing at 11,12 , or 13 inches, so that, taking the normal number of females for every 100 males to be 117 , as explained in the preceding section, we must explain the relative excess of males below 14 inches as due to retarded growth of the males in excess; but the increasing relative deficiency of males above 14 inches in length must be due to a large extent to actual arrest of growth, since the normal proportion of males to females is never realized in groups of fish measuring more than 14 inches in length.

The minute economy which prevails among species under natural conditions of existence is clearly revealed by the facts established in the preceding paragraphs; for it is obvious that, ceteris paribus, the equivalent growth of males and females would lead to an increasing superfluity of the male reproductive elements, owing to the great difference in size between an ovum and a spermatozoon.

It remains to add that the average size of 423 males recorded in the tables is 12.988 inches; that of the 495 females, 13.145 inches. Consequently, if the average size of the males be taken as 100 , that of the females becomes 101. The difference between the size of mature males and females is probably a little greater than this, but the subject of maturity in the mackerel is reserved for a later report.

$\S 4$. Secondary Sexual Characters. Apart from size, I have been unable to discover any evidence whatever of the existence of secondary sexual peculiarities in the mackerel. My investigations of this point will be found under the special sections dealing with the shape of the Transverse Bars (p. 261), the Dorso-lateral Intermediate Spots (p. 263), and the First Dorsal Fin (p. 267). With the exception already mentioned, I can therefore repeat the remark of Smitt that "all the statements as to an external difference of sex in the mackerel which have been made up to the present have proved untrustworthy on closer examination" (Scandinavian Fishes, I. 1892, p. 112).

\section{Number of Transverse Bars.}

$\S 1$. The Entire Series. The frequency of the variations in the entire number of transverse bars in the various local samples and in certain chosen combinations of these is set out in Table B. (p. 290).

The extreme range of variation is from 23 to 33, i.e., 11 bars.

The modal (i.e., most frequent) number is almost invariably 27 , there being only three exceptions to this rule among 21 samples, viz., Scilly, June 9th, (50 fish), Kinsale, July 1st (100 fish), and Brandon, April 
16th, (45 fish). Two of these samples, it will be noticed, are small: in one the modal number is 26 , in the other 28 .

The first impression made upon a survey of the figures in the table is undoubtedly the slight nature of the differences in the range and frequencies of variation in the different samples. But the next impression is the remarkable constancy with which mean-values of less than 27 are associated with samples from localities in the North Sea and English Channel, while the means for the Irish and American samples exceed that figure with only one exception. This indicates, as can easily be seen by comparison, that in North Sea and Channel samples the values below 27 always occur more frequently than those above 27; while in the Irish and American samples, with only one exception, the reverse is the case.

For North Sea and Channel samples, the means vary from 26.50 to 26.94 , and, for Irish samples, from 26.90 to $27 \cdot 56$. The American mean is $27 \cdot 38$.

If we exclude all samples of less than 90 fish, the means, taken in the same order, vary from $26 \cdot 62$ to 26.91 , and from 26.90 to $27 \cdot 32$.

Analysing this contrast still further, by means of the table of percentages for the local groups (neglecting groups of less than 200 fish), we see that the frequency of the value 26 varies from $30 \%$ to $31 \%$ in the case of Lowestoft and Plymouth, but from $21 \%$ to $23 \%$ in the case of Kerry and Kinsale. Similarly the frequency of the value 28 varies from $14 \%$ to $15 \%$ for Plymouth and Lowestoft, but from $23 \%$ to $25 \%$ for Kinsale and Kerry. The frequency of the modal value 27 is constant at $38 \%$ for the two Irish groups, but varies from $38 \%$ to $42 \%$ for Lowestoft and Plymouth.

The conclusion is irresistible that the Lowestoft and Plymouth fish resemble one another very closely, and that the Kerry and Kinsale fish do so likewise, but that there is a comparatively serious difference between the Irish fish and those from the North Sea or Channel.

Hitherto, however, we have not taken into consideration the actual frequencies of the extreme values (i.e., those below 26 and above 28). These values occur very rarely, and their separate frequencies cannot consequently be compared with exactitude in samples of ordinary magnitude. To bring their frequencies into consideration, it will be necessary to merge all the extreme values into two groups, one of low, and the other of high value, and to compare the frequencies of the combined values. This has been done in the following condensed table, in which, also, the Ramsgate data have been combined with the Lowestoft records to form a single group representative of the North Sea, and Brest has been combined with Scilly. No one, I imagine, will be prepared, on the evidences provided in this report, or on any other 
grounds, to regard the Ramsgate autumn fish as anything but the southern extension of the Lowestoft shoals. The Scilly data closely resemble those from Brest in many respects, and the combined data may be regarded as representing the mackerel off the mouth of the Channel during June.

TABLE IV., showing frequencies of values of Transverse Bars.

(Percentages.)

\begin{tabular}{|c|c|c|c|c|c|c|c|}
\hline & & $\begin{array}{l}\text { Number of } \\
\text { Fish. }\end{array}$ & $\begin{array}{l}23 \text { to } \\
25\end{array}$ & 26 & 27 & 28 & $\begin{array}{c}29 \text { to } \\
33\end{array}$ \\
\hline Newport, U.S.A. & . & 100 & 6 & 13 & 37 & 28 & 16 \\
\hline North Sea & . & 400 & 9 & 29 & 42 & 15 & 5 \\
\hline Plymouth & . & 300 & 8 & 30 & 42 & 14 & 6 \\
\hline Brest and Scilly & . & 174 & 5 & 32 & 41 & 17 & 5 \\
\hline Kinsale . & . & 410 & 5 & 23 & 38 & 23 & 11 \\
\hline Kerry . & . & 245 & 3 & 21 & 38 & 25 & 13 \\
\hline
\end{tabular}

This table strikingly confirms the conclusions already drawn. The resemblance between the percentage frequency of the different values in the case of Plymouth and North Sea fish amounts practically to identity, and the resemblance between the same data for Kinsale and Kerry fish is almost equally exact. The combined Brest and Scilly data also closely resemble the North Sea and Plymouth records.

On the other hand, the American and the two Irish groups diverge considerably from the others in the low percentage of the low values and in the high percentage of the high values, and the American sample shows this contrast still more markedly than the Irish groups.

From the variation of this character, therefore, I conclude that the mackerel examined fall into three groups, characterised by differences in the frequency of high and low values of the transverse bars. These groups, arranged in order of frequency of the high values, are:-

1. American, in which $44 \%$ of the fish have 28 or more bars each.

2. Irish, in which the number of fish having the same high number of bars varies between $34 \%$ and $38 \%$.

3. English Channel and North Sea (including Brest and Scilly), in which the number of fish having the high number of bars varies between $20 \%$ and $22 \%$.

I also conclude that these differences indicate a racial separation between the three groups. The American fish are shown in the sequel to be distinguishable from European fish in regard to every character, so that I do not anticipate that my conclusion as to the 
existence of a peculiar American race of mackerel will be disputed. But the differences between the Irish and the Channel fish are not so sharply defined in all respects as those between the American and European, so that the same degree of certainty cannot be attached to my conclusion as to the existence of a separate Irish race. Nevertheless, I would point out that, if the racial distinctness of the American fish be admitted, it is impossible to avoid a similar conclusion in regard to the Irish fish also, if we confine our attention to the evidence of the variation of the transverse bars, for the difference between the Irish and Channel samples is greater than the difference between the Irish and American, and is almost as great as the difference between the American and the European as a whole.

Moreover, the general difference between the Irish and English fish is not confined to the gross samples from these localities as a whole-in which case it might be attributed to errors of observation or calculation-but it has been shown to be also characteristic of the numerous individual samples of fish from these localities, almost without exception. This fact, in my opinion, is one of very great importance.

It must also be stated that the differences between the samples are not due to any increase in the number of bars with the growth of the fish. This can be inferred merely by comparing the sizes of the fish in the different samples. Thus the highest mean number of bars occurs in the American sample, which consisted almost entirely of relatively small fish, while the lowest mean number occurs in the Lowestoft sample, dated June 28th, in which the distribution of sizes was practically identical with that in the American. (See Table A.) Again the values are almost equally high for the Kinsale samples as for the Kerry samples, although the former consist exclusively of small fish, and the latter exclusively of large fish.

The following facts which I have ascertained point unequivocally to the same conclusion.

The transverse bars are formed at an early period, and the basis of their formation is a deposit of pigment along the free surface of the myotomes. It is this relation to the myotomes which gives the bars in the majority of cases a marked $>$ shaped curvature. Now the number of myotomes corresponds to the number of vertebræ, which is almost invariable in most species of bony fishes, and particularly so in the mackerel. From the relation of the bars to the myotomes it may, accordingly, be assumed that no change in their number takes place after formation.

If the correspondence between transverse bars and myotomes were perfect, the number of the bars would be the same as the number 
of vertebræ, and equally invariable. This is obviously not the case. But it is important to notice that the average, or rather modal, number of bar's is exactly the same as the number of vertebrce. The modal number of bars between shoulder girdle and last dorsal finlet is shown in my tables to be 27 . The total number of vertebræ in the mackerel is 31. But the vertebral column extends a little in front and a little behind the limits mentioned, and by dissection I have found that this excess coincides with the extent of the two anterior and the two posterior vertebræ. Consequently the number of vertebræ in the region corresponding to the bars enumerated is four less than the total number, viz., 27, which is also the modal, or most frequent number of bars. This correspondence furnishes a conclusive confirmation of the general accuracy of my data in regard to the present character, as well as of my statement that the bars are formed in relation to the myotomes. The variation in the number of bars is due to the fact that the pigment is not deposited in a regular manner along the free surface of the myotomes, except in very rare cases. In most fishes the pigment streak can be seen to correspond with a particular myotome for part of its extent, and then to become broken or discontinuous, either remaining as an isolated fragment, or more frequently effecting an abrupt anastomosis with the pigment of a neighbouring myotome. These two facts, the discontinuous deposition of pigment along the myotomes, and the irregular anastomosis of the pigment streaks of neighbouring myotomes, account not only for the variable shape of the transverse bars, but also for their variable numbers. The variation in the number of the bars, in spite of the fundamental relation between the bars and the myotomes, does not involve any variation in the number of the myotomes or vertebræ. But, just as the number of myotomes is fixed for each fish, so the number of pigment-bars which are formed in connection with them is not subject to alteration after the period of formation. This period falls between the metamorphosis of the larva and the acquisition of a length of some 4 or 5 inches.*

To remove all doubt concerning this important point, I have calculated the mean number of bars in all the very small fish taken at Plymouth during the autumn of 1897 . The total number of fish was 67 , ranging in length from $5 \frac{1}{2}$ to 10 inches. The mean number

* It is curious to notice that the transverse bars of the adult mackerel occupy a position in relation to the myotomes which is quite different from that occupied by the vertical lines of chromatophores in young mackerel from 14 to $18 \mathrm{~mm}$. in length, according to Holt's description and figures (this Journal, V., 1898, p. 116, figures 3 and 4). In preserved specimens at this early stage Holt states that, "on the sides of the trunk, the chromatophores are set more thickly at the lines of division of the myomeres than elsewhere," i.e., along, instead of between, the septa which separate the myotomes. 
of the bars was 26.66 , a number well within the range of the means for North Sea and Channel samples, viz., from 26.50 to $26 \cdot 94$.

\$2. The Bars which cross or meet the Lateral Line. The frequency of the variations in the number of these bars is given in Table $\mathrm{C}$ (p. 291).

It will be noticed that, in spite of the greater exactitude with which the number of these bars can be determined, the range of variation is distinctly greater. In the case of the entire series the range covered only 11 bars; in the present case the range is from 12 to 25 , and covers consequently 14 bars. When it is remembered that in the former case the whole side, and in the present case only a part of the side of the fish, was under examination, the observed difference in the range of variation must be regarded as significant. I attribute the difference to the fact that the field occupied by the bars in the first case is invariable, being the whole side of the fish, while that which provides the material for variation in the present case is in itself variable. The anterior boundary is fixed by the shoulder-girdle, as in the entire series; but the posterior boundary of the field depends on the curvature of the lateral line in that part of the body. The place where the bars cease to meet the lateral line generally coincides with an abrupt downward bend in the course of the line; but, as the bend is sometimes absent, or takes place in front of, or behind, its usual position, the number of bars which meet the line is correspondingly increased or reduced.

The number of bars affected by this irregularity in the curvature of the lateral line is not great, and the error which is introduced by it into the records of the variability of the number of bars consequently tends to become smaller and smaller as the number of observations is increased. But, as the mean values in Table $\mathrm{C}$ show, it is sufficient to break down the high uniformity of results between the unitsamples of any one region which was exhibited in Table B.

Excluding the two small samples of 12 fish from Scilly, the modal number is seen to be usually 18; but the exceptions to this rule are more frequent in the present case than for the entire series, being 6 instead of 3 .

The means for the samples from Lowestoft, Ramsgate, and Plymouth vary from 18.03 to 18.58 ; for Scilly and Brest from 18.64 to 18.65 , and for the Irish samples from $18 \cdot 15$ to $18 \cdot 62$. The American mean is 18.88 .

If we exclude all samples of less than 90 fish, the means for the North Sea and Channel vary from 18.04 to 18.43 , those for the other localities being unaffected.

Thus the American mean, as before, is the highest, and the lowest means are found among the North Sea and Channel samples, as was also the case for the entire series of bars; but the contrast between 
the Irish and the Channel means is much less emphatic for the partial series than for the entire series of bars, owing to the more extended range of the mean values for both localities.

The explanation is, I believe, the same as for the greater range of variation of the partial series as compared with the entire series, viz., the irregularity introduced by the variability of the lateral line, which renders the number 100 insufficient as a unit-sample. If this is so, a closer approach to the former result ought to be revealed by comparing the means of the local groups of fish as a whole, neglecting groups of less than 200 fish. These means in fact for the Lowestoft and Plymouth groups vary from 18.21 to 18.23, and for the Kinsale and Kerry groups from $18 \cdot 37$ to $18 \cdot 45$, thus displaying a close agreement between the Lowestoft and Plymouth fish, and also between the Kinsale and Kerry fish, but a considerable difference between the Irish fish and those from the North Sea or Channel.

This relation is precisely the same as that revealed by the variation of the entire series of bars, the means for the North Sea and Channel being lower than those for the Irish groups in each case.

It is interesting to notice also that the close approximation between the Brest and Scilly means in regard to the entire series of bars is again shown in regard to those which meet the lateral line; but whereas the combined mean for Brest and Scilly only slightly exceeded that for the North Sea and Plymouth in the former case, here it is actually higher than the Irish mean. The significance of this difference it is impossible to decide at present, as the total number of fish from Brest and Scilly only amounts to 174 , a number which cannot be regarded as sufficient to neutralise the error due to the curvature of the lateral line. If the mean, however, be provisionally accepted as approximately correct, it points to the conclusion that in some respects the mackerel which are found off the mouth of the English Channel and the neighbourhood of Ushant in June may form a connecting link between the Irish fish and those of the North Sea and Channel. From the geographical relations of the areas under discussion such a result would certainly accord with a priori expectations.

The percentages of frequency of high and low values of the bars may best be understood from the following condensed table :- 
TABLE V., showing frequencies of values of partial Series of Bars. (Percentages.)

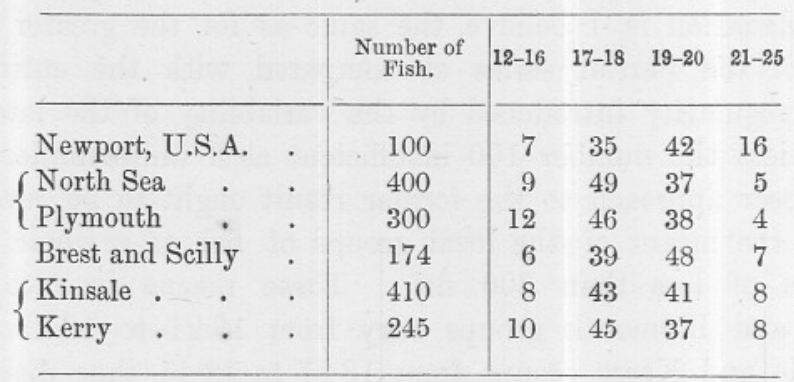

We see from this table that the combined percentages in the two right-hand columns exceed those in the two left-hand columns in only two cases, viz., Newport, and Brest and Scilly. This preponderance of high values over low values corresponds to an excess of the mean values above 18.5 .

In all other cases the figures in the two left-hand columns exceed those in the two right-hand columns. This preponderance of low values corresponds to mean-values less than 18.5 .

The figures for the North Sea and Plymouth again correspond with remarkable exactitude, as also do those for Kinsale and Kerry. The difference between the Irish values and those for the groups from the North Sea and Channel is not great, but it is distinctly greater than the difference between the North Sea and Plymouth groups inter se, or between the groups from Kinsale and Kerry. The column which contains the highest percentages for each of these four localities is that recording the frequency of the numbers $17-18$; and it will be seen that while the frequency of these values varies from $46 \%$ to $49 \%$ for the North Sea and Plymouth, it does not exceed $45 \%$ for Kinsale and Kerry.

In this connexion it should be noticed that both the minimum and maximum frequencies of the lowest values $(12-16)$ are lower for the Irish groups than for the North Sea and Plymouth. On the other hand, the highest values of all (21-25) occur twice as often among Kinsale and Kerry fish as among North Sea and Channel fish, viz., $8 \%$, as compared with $4 \%$ or $5 \%$. This contrast in regard to the distribution of high and low values can be looked at in another way, viz., by comparing the relative frequency of the highest and lowest values in each group of fish. Thus in the American fish the frequency of the highest values is more than twice as great as that of the lowest values $(16: 7)$; for Brest and Scilly it is barely in excess $(7: 6)$; for Kinsale 
and Kerry the frequencies of the highest and lowest values are approximately the same $(8 \%)$; while for the North Sea and Channel the lowest values are twice or thrice as frequent as the highest values $(9: 5$ and $12: 4)$.

So far, therefore, as concerns the main conclusions drawn from the variation of the entire series of bars, the variation of the partial series furnishes a fairly satisfactory confirmation. These conclusions were the existence of three main races of mackerel in American and British waters, viz. (1) an American, (2) an Irish, and (3) a race common to the North Sea and the Channel.

The only respect in which the results are at variance concerns the affinities of the fish from Brest and Scilly, which were clearly with the Channel and North Sea fish for the entire series of bars, and with the Irish fish for the partial series. Nothing but the examination of a larger number of fish from this region will solve the difficulty. Additional facts, however, are adduced in the sequel which tend to show that the Brest and Scilly fish are intimately related to those of the Channel and North Sea, but show, under each character examined, a slight approximation towards the Irish race.

\section{Shape of Transverse Bars.}

The cause which determines the general shape of the transverse bars has already (p. 256) been discussed, and has been found to be the deposit of pigment along the external surface of the myotomes. As the myotomes in the dorsal half of the body have a marked $>$ shaped, or geniculate, curvature, the bars consequently show a marked tendency to assume a corresponding shape. The breaks and anastomoses, to which the bars are subject at the time of their formation, show, however, such diversity and complexity of form that they defied all my earlier efforts to discover a suitable system of classification by which the vagaries in the shape of the bars might be recorded for subsequent comparison.

I began by noting whether the general arrangement of the bars was regular or irregular, adopting several grades of regularity and irregularity to cover the intermediate conditions; but, although I have a complete set of data in these terms, and have tabulated the results for comparison, the examination which I have made of them shows them to be practically worthless for exact conclusions. This is largely due, as I now know, to the fact that regularity in the bars, i.e., parallelism, with an absence of breaks and bifurcations, may be of two very distinct kinds, which may be termed, for comparison, primary and secondary. Primary regularity is due to the bars having retained their 
fundamental relations to the myotomes; they are not only parallel and unbroken, but also geniculate in shape. Secondary regularity is caused by the anastomosis of portions of the pigment streaks of neighbouring myotomes in such a regularly repeated manner as to produce an equally marked parallelism of arrangement, coupled with a partial or complete loss of the typical geniculate curvature and relation to the myotomes. Thus a parallel series of vertical, or oblique, bars is frequently exhibited; and in such a case each bar upon dissection has been found to cross several adjacent myotomes, instead of following any individual myotome along its course. By grouping those two types of arrangement under the same head "regular," I was unwittingly uniting things which should have been poles asunder.

On discovering this error, I proceeded to record the general shape of the bars in addition to their degree of regularity; but it would be unprofitable on the present occasion to give a general account of these later observations, owing to the fact that the majority of the fish examined during the autumn of 1897, including the bulk of the fish from Kinsale, would have to be omitted from consideration.

It has, however, been asserted by Donovan ( fide Day, British Fishes, Vol. I. p. 84) that the sexes can be distinguished by the shape of the bars, these being "straight" in the male and "undulated" in the female. As my observations are amply sufficient to test the accuracy of this statement, I give some figures bearing on the question. As the term "undulated" is somewhat ambiguous, and may be held to apply to the angular > shaped, or geniculate, bars, as well as to those of a more truly wavy, or convoluted type, I have determined the proportion of the sexes exhibiting each of these characters, in addition to the proportion exhibiting straight or vertical bars. To avoid all doubt, I have eliminated all cases except those in which the bulk of the bars could be definitely described as either geniculate, wavy, or straight.

The results are shown in the following table:-

TABLE VI., showing Shape of Bars in relation to Sex.

\begin{tabular}{|c|c|c|c|c|c|}
\hline \multicolumn{3}{|c|}{ Shape of bars. } & $\begin{array}{c}\text { Number of } \\
\text { Fish. }\end{array}$ & $\sigma^{\pi}$ & $q$ \\
\hline Geniculate & . & . & 75 & 34 & 41 \\
\hline Wavy . & . & • & 78 & 36 & 42 \\
\hline Straight . & . & • & 72 & 26 & 46 \\
\hline & & . & 225 & 96 & 129 \\
\hline
\end{tabular}


The figures in the table completely disprove the accuracy of Donovan's statement, and show, once for all, that the shape of the bars is entirely independent of the sex of the fish.

The percentages of the total numbers of males and females examined are $43 \quad \delta$ and 57 \% ; and for the first two types of bar this proportion is almost exactly reproduced, being $45: 55$ for the geniculate bars, and $46: 54$ for the wavy bars. So far from the straight bars being distinctive of male fish, there is a slight preponderance of females showing this character, the proportion being $36 \sigma$ to $64 q$. For a total of $72 \mathrm{fish}$, however, this proportion is sufficiently close to the total proportion of males to females to show the entire absence of sexual peculiarities in the matter.

\section{Dorso-Lateral Intermediate Spots.}

The general character of these spots has already been given in the description of the characters investigated (p. 241). They are, strictly speaking, discontinuous portions of the pigment streaks of the myotomes, but they assume so definite a shape, and possess such clearly-defined relations to the transverse bars, that it is possible to discuss the variations in their frequency independently of the bars of which, theoretically, they form a part.

No fragments of the bars are here considered as "intermediate spots" unless they possess a sharply-defined round or elliptical shape, and unless they are situated between two neighbouring transverse bars, or are entirely or partly enclosed in a ring-like modification of two neighbouring bars.

It sometimes happens that the extremities of the bars are separated off as small "end-pieces," which may even assume a rounded form. Such end-pieces are undoubtedly connecting links, from a theoretical point of view, between perfectly linear and continuous bars and the pigment-spots which I distinguish as "intermediate"; but if these end-pieces plainly continue the lines of the bars, and do not occupy an isolated intermediate position between two adjacent bars, they have been excluded from consideration.

The importance which I attach to the extreme type of "intermediate spots," as defined, rests on the following grounds. The shape and course of the bars is fundamentally determined, as already shown, by the shape and course of the myotomes or muscle-segments. Bars, therefore, which follow the course of the myotomes may be regarded as primitive in character. In such cases, since the surface of every myotome is occupied by a pigment-streak, it is clear that spots, having an intermediate position between two adjacent bars, can have no 
existence. Spots of this kind can only be found in fish whose transverse bars have departed from their primitive relation to the myotomes, and in which the primitive symmetry has been replaced by a new symmetry, due to the breaking up of the primary bars and the anastomosis of the fragments of one bar with those of its neighbours. Some of these fragments remain permanently isolated, and constitute the intermediate spots under discussion; while to right and left of them are seen the new or "secondary" bars which have resulted from the union of the other fragments of the primary bars.

Thus the presence of intermediate spots is in itself evidence of the transformation of the primary bars, and the frequency of these spots in races of fish may be expected to vary according as the process of transformation has proceeded to a greater or less extent.

A comparison of the markings of the different species of the genus Scomber shows, indeed, that they are subject to extraordinary modifications. Thus, according to Günther's catalogue (vol. ii., pp. 357-362), the stripes are transverse in $S$. scomber, pneumatophorus, janesaba, and tapeinocephalus, irregularly reticulated in $S$. colias, longitudinal in S. chrysozonus, replaced by longitudinal rows of spots in $S$. moluccensis, and of indistinct dots in S. microlepidotus. Why the transverse stripes should be retained in one species and replaced by longitudinal stripes in another, I am unable at present to say; but it is evident that the markings of the mackerel tribe are, so to speak, in a state of very unstable equilibrium, and susceptible of considerable modification, a fact which should render them of much service in the investigation of racial differences in the more primitive species. To this group the common mackerel belongs, owing to its retention of the transverse stripes, modified though these are in a variety of ways.

The variations in the frequency and numbers of the intermediate spots are given in Table D (p. 292).

The number of fish exhibiting one or more spots (which for brevity will be termed "spotty fish") is seen, as a rule, to be but a small proportion of the whole; but in this respect there is a striking contrast between the European and the American mackerel. In European samples the number of spotty fish is usually about $25 \%$ of the whole, varying from $7 \%$ to $29 \%$; but in the American sample the spotty fish predominate, and amount to $66 \%$ of the total number.

Similarly the total number of spots for every hundred fish is usually about 30 in European samples, varying from 8 to 57 , but attains the extraordinary total of 215 in the American sample. The table giving the frequency of the different numbers of spots shows that the high American total is not due to the accidental inclusion of some one or two very spotty fish, but is due to a regular and extensive variation 
in regard to the number of spots, the numbers from 1 to 11 occurring with a frequency which decreases fairly regularly as the number of spots increases. In one fish actually 17 spots were enumerated.

It is not to be expected that a character which is altogether absent in $75 \%$ of the fish would show any great uniformity of variation in samples of only 100 fish.

The range of variation in the samples, excluding those of less than 70 fish,* is, however, as follows :-

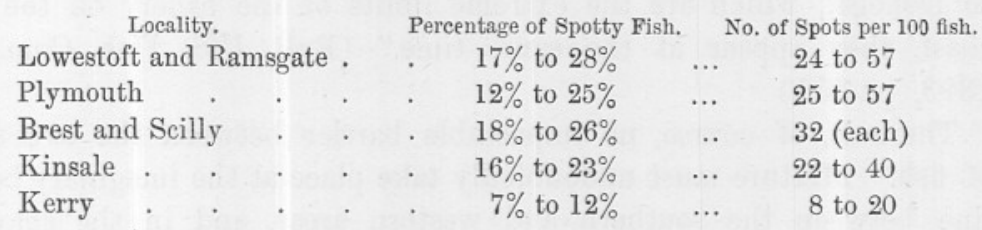

As we have already seen for previous characters, so here in regard to spottiness, the table brings out the close relationship between the North Sea and Plymouth fish with a fidelity which is really astonishing; and the close affinity of the Brest and Scilly fish with those of the former regions is also clearly shown. The novel feature of the table is the remarkable difference between Kinsale and Kerry fish in regard to this character, those of the West coast of Ireland having a very low degree of spottiness, while those of the South coast occupy an intermediate position between the Kerry fish and those of the Channel, approximating, however, more closely to the latter. The maximum percentage of spotty fish in the Kerry samples scarcely attains to the minimum percentage in the samples from every other region, and the maximum number of spots per hundred fish is actually less than the minimum number for other localities.

The reliability of the data as a test of racial peculiarities is established in my opinion by the close conformity of the results in regard to the North Sea and Plymouth fish, since these are groups the racial identity of which is rendered antecedently probable by the sequence of events in the fishing seasons, and by geographical and physical considerations. This antecedent probability has already been confirmed by the results described in the section on the number of transverse bars.

The sensitiveness of the character as a test of racial differences is also confirmed by the great contrast which has been shown to exist between American and European fish in regard to this character, a contrast which is borne out by the variation of almost every other character, but which is more striking for this character than for the remainder.

* The small Brandon sample, dated April 16th, has been combined with that dated April 22nd, in order to obtain a representative percentage for this locality. 
The conclusion, therefore, seems to me to be inevitable that the mackerel which frequent the south and west coasts of Ireland are not a single stock of fish which visit both coasts indifferently, but are separable into two stocks, one of which inhabits the waters off the west coast, the other those off the south coast.

I find some support for this conclusion in Mr. Green's statement that he has met with no evidence to show that mackerel in approaching the Irish coast "travel along it, either to north or south. From Cork to Donegal, which are the extreme limits of the fishery on the Irish coast, they appear at the same time." (Bull. U.S. Fish Com., xiii. 1893, p. 358.)

There is, of course, no impassable barrier between the two stocks of fish. Mixture must undoubtedly take place at the imaginary borderline between the southern and western areas, and in the spawning season a variable number of the floating eggs from one stock must be carried by currents into the area of the other; but it must be remembered that my samples are derived from localities relatively far apart, viz., Kinsale and off the mouth of the Shannon, and that while the west coast fish are only subject to mixture with the closely related south coast fish, those which are found in the eastern waters of the south coast are also liable to mixture with the mackerel of the English Channel. It is probably significant, therefore, that the differences between the Kinsale and Kerry fish consist in an approximation of the former fish, and not of the latter, towards those of the Channel in regard to the present character.

I may draw attention to the fact that this intermediate condition of the Kinsale fish is not confined to the present character. If reference is made again to Table $\mathrm{B}$, it will be seen that the mean number of transverse bars is distinctly lower for Kinsale $(27 \cdot 15)$ than for Kerry (27.27), and consequently approximates towards the mean value for the Channel, which is the lowest of all (26.79). In this character, however, the Kinsale fish maintain a closer resemblance to the Kerry fish than to those of the Channel. Similar results have also been yielded by the first dorsal fin, as will be described later on (p. 275).

From a comparison of all three tables (B, C, and D) it would appear to be probable that the mixture which actually accounts for the intermediate condition of the Kinsale fish is rather with the Brest and Scilly fish than with those of the Channel in its narrower sense. Such a conclusion would harmonise well with the known range in the position of the fishing quarters during the spring season.

To conclude this chapter, I give a more condensed statement of the results for the four principal regions. 
TABLE VII., showing variation in Spottiness.

\begin{tabular}{|c|c|c|c|c|c|c|c|c|}
\hline \multirow{2}{*}{\multicolumn{2}{|c|}{ Locality. }} & & \multirow[b]{2}{*}{$\begin{array}{l}\text { Number } \\
\text { of Fish. }\end{array}$} & \multicolumn{3}{|c|}{ Percentage of Spotty Fish. } & \multirow{2}{*}{$\begin{array}{l}\text { Total } \\
\text { number of } \\
\text { spots per } \\
\text { 100 Fish. }\end{array}$} \\
\hline & & & & & Total. & $\begin{array}{l}\text { Fish with } \\
1 \text { spot. }\end{array}$ & $\begin{array}{l}\text { Fish with } \\
2 \text { or more } \\
\text { spots. }\end{array}$ & \\
\hline $\begin{array}{l}\text { America . } \\
\text { North Sea and English } \\
\text { Brest and Scilly } \\
\text { Ireland, W. and S. }\end{array}$ & $\begin{array}{c}\text { Channe } \\
. \\
.\end{array}$ & & $\dot{.}$ & $\begin{array}{l}100 \\
700 \\
174 \\
556\end{array}$ & $\begin{array}{l}66 \\
21 \\
22 \\
15\end{array}$ & $\begin{array}{l}23 \\
13 \\
15 \\
11\end{array}$ & $\begin{array}{l}43 \\
8 \\
7 \\
4\end{array}$ & $\begin{array}{c}215 \\
37 \\
32 \\
23\end{array}$ \\
\hline
\end{tabular}

This table brings out clearly (1) the decisive racial distinctness of the American fish, (2) the affinity between the fish from Brest and Scilly with those of the Channel and North Sea, and (3) the racial difference between the Irish fish and those of the preceding area.

In general terms it may be said that the American fish are very spotty, and the Irish fish, particularly off the west coast, are very free from spots, while the fish which frequent the English Channel, from its mouth to the coast of Norfolk, have a somewhat higher percentage, both of spots and spotty fish, than those of the Irish coast.

That spottiness has no connexion with the size of fish examined is clear from a comparison of the results with the table of sizes.

The following figures prove the absence of any sexual peculiarities in the matter. They are based on the entire set of samples in which the sex of the fish was recorded, i.e., 100 American and 918 British fish.

American fish.-Proportion of males to females . . . 55:45 " $\quad$ male to female spotty fish . . . $59: 41\}$

British fish.-Proportion of males to females $\quad \begin{gathered}\text { Deviation }=4 \% \\ \cdot \quad 46: 54 \\ \quad\end{gathered}$

Deviation $=2 \%$

\section{Number of Finrays in First Dorsal Fin.}

According to Günther's Catalogue of Fishes (vol. ii., p. 357), the number of finrays in the first dorsal fin of the common mackerel is higher than in any other species of the genus Scomber, and varies from 11 to 14 . The lowest number is presented by the Spanish mackerel (S. colias), which is stated both by Günther and Day (British Fishes, i., p. 91) to possess only 7 rays. An intermediate condition is shown by $S$. pneumatophorus, which possesses 10 rays, according to the same authorities. Steindachner, on the other hand, regards the two latter forms as varieties of one and the same species, in which the number of finrays would vary accordingly from 7 to 10 . From an examination of several specimens from the Mediterranean, which I owe to Professor NEW SERIES, - VOL, Y. NO. 3. 
Marion's kindness, I am inclined to agree with Steindachner in the matter. In any case, there is a marked difference in the number of finrays characteristic of the common and the Spanish mackerel, the two best known species of the genus Scomber. If there are any separate races of the common mackerel, there exists, accordingly, an a priori probability that the distinction between these races will include differences in regard to the number of rays in the first dorsal fin, especially as the variability of this character in $S$. scomber is already known to be considerable.

Before proceeding to an examination of my results, I should state that the determination of the exact number of rays present in the first dorsal fin of any mackerel is a matter requiring considerable care, owing to the minuteness of the posterior rays. The second or third ray is usually the longest, and the length of the remaining rays decreases gradually to zero. If one wished to omit the minute hinder rays from consideration, it would be as difficult to determine a just arbitrary limit as to endeavour to count the entire series. I have therefore adopted the latter course, and my figures represent the maximum number of finrays recognisable in each fish without actual maceration.

Upon a first inspection of the figures representing the average number of rays in the fish from each locality, I feared, from their apparent irregularity, that the difficulties of exact determination had proved too great for the acquisition of definite results, and this remark was made in the preliminary account of my researches communicated to the British Association at Bristol. From the more complete analysis of the figures, however, which I now provide, it will be seen that my fears were groundless, for the data have proved to be of sufficient exactitude to establish an unexpected but convincing relation between number of finrays and size of fish.

$\S 1$. General variation. The distribution of finray values among the various consignments of mackerel examined is given in Table $\mathrm{E}$.

The range of variation is shown to be from a minimum of 9 rays to a maximum of 16 rays, but in a total number of more than 1600 fish the former value was only found twice and the latter value only once. The most frequent value was 12 , which was found in about half the fish examined; 13 rays were found in about one quarter of the fish, and the remaining quarter consisted principally of fish possessing 11 and 14 rays, the former value being much more frequent than the latter. The fish with $9,10,15$, and 16 rays formed a very small percentage of the whole (about $3 \%$ altogether).

§2. Local differences. In a sample of 100 fish from the French coast near Brest, the variation of finray values was absolutely symmetrical 
(see Table E, p. 293), and exactly $50 \%$ of the fish exhibited the modal or most frequent value.

In all other samples the distribution of values was asymmetrical. The percentages for the various localities show that the modal value is 12 for all localities except Scilly, for which it is 13 . This exception is no doubt paríially due to the smallness of the consignments from that locality (only 74 fish in all), and is paralleled by a similar phenomenon in the case of a small consignment from Brandon, April 16th, in which the most frequent value was 11, although 12 in a subsequent and larger sample.

For most localities the number of fish having 13 rays preponderates over the number having 11 . This is true for Lowestoft, Ramsgate, Plymouth, Scilly, and County Kerry. But the American fish show a slight preponderance of the lower value, and the preponderance of this value is considerable in the case of the fish from Kinsale. In this respect the Kinsale fish differ from those from all other British localities, and the matter requires special consideration.

On examining the data for the various samples received from Kinsale (Table E), it is seen that the preponderance of low values was not exhibited by all the consignments, those taken on September 17th, 1897, and July 1st, 1898, being normal in this respect. The preponderance of low values was entirely due to the samples dated July 30 th and September 3rd, 1897. Now these were the only samples in the whole series of fish which were not examined in a fresh condition. They arrived during my absence in Canada, and after measurement were placed in tanks of formaline to await my return. The excess of low values is so unique in these two cases that I consider myself justified in attributing the difference to the effects of this re-agent, the tendency of which to develop free formic acid is well known. The amount of calcareous matter in the minute posterior rays is so small, that its solution by the acid would be merely a matter of time. As the fish remained six weeks in the formaline before examination, there can be little doubt that the calcareous matter in the smallest rays was dissolved in a certain number of cases to an extent sufficient, at any rate, to invalidate the records. The omission of the posterior ray from $20 \%$ of the fishes in these samples would be more than sufficient to account for the observed differences between the fresh and preserved samples of Kinsale fish.

If this correction be permitted, the variation of the first dorsal fin becomes very uniform for all British localities, with the exception of Scilly, an exception which is readily explicable by the inadequacy of the sample from that region. The numbers of finrays vary round 12 as a mode, and the percentage of values above the mode tends 
everywhere to exceed the percentage of values below it; but neither by a comparison of the percentages themselves, nor by the study of the average values for each locality, is it possible to trace any marked evidences of racial distinction among the British fish. The American fish alone seem to possess any distinguishing peculiarity as regards the variation of this organ.

The question, however, is complicated by the factors of growth and sex. Matthews has shown that in the herring there is a slight increase in the number of dorsal finrays with the growth of the fish, an increase which is not so much due to the appearance of new rays as to the enlargement of the minute anterior ray, which renders it less liable to escape notice in large fish than in small (4th Report Scottish Fishery Board, 1886, p. 92). It is therefore necessary to enquire whether there exists any similar relation in the mackerel between size of fish and number of recognisable rays.

Moreover, the first dorsal fin is frequently modified as a secondary sexual character in bony fishes, and although no such modification has ever been recognised in the mackerel, it is important to ascertain whether or not the number of rays is correlated with sexual distinctions. The proportion of the sexes in the various consignments of fish examined was not always uniform, and, if any correlation exists, the preponderance of opposite sexes in two different samples would occasion a difference in the results which might be readily mistaken for evidence of racial peculiarities.

§3. Number of Finrays according to Sex and Size. The sex of the fishes examined during the autumn of 1897 was not always determined, so that in the present enquiry we shall be restricted to the following samples of fish :-

\section{Ireland.}

(1) Kinsale, July 1st, 1898 . . . 44 males and 56 females

(2) Smerwick, March 12th, 1898 . 63 " " 36 ,

(3) Brandon, April 16th, 1898 . . 20 " " 25 ",

(4) " " 23rd ". . 43 " , 58 "

Total . 170 , , 175 ,

\section{English Channel and North Sea.}

(1) Plymouth, Nov. 16th to 20th, 189741 males and 59 females

(2) " July 6 th, 1898 . . 42 " " 58 "

(3) " "11th " . . 10 " " 14 ",

(4) Ramsgate, Oct. 27th, 1897 . . 55 " " 45 ",

(5) Lowestoft, Oct. 12th " . . 15 " " 10 "

(6) " June 28th, 1898 . $21 \quad$ " " 29 ,"

(7) " July 12th " . 39 " " 61 "

Total . . 223 " " 276 "


The size of the fish in these samples, irrespective of sex, is given in inches and quarters in Table $\mathrm{A}$. In the enquiry before us, however, it is inadvisable to have too many size-groups, as that would reduce the number of fish in each group to a very small number. I have therefore subdivided the Irish males and females into groups according to the integral number which expresses the length of each fish in inches, the fractional differences being neglected. The fishes in each group have then been sorted according to the number of the rays in their dorsal fins. The same has been done with the males and females of the Channel and North Sea fish, and the resulting distribution of values is shown in Table F (p. 294). The upper half of the table represents the observed frequency of the various finray values, the lower half embodies the same facts reduced to percentages. The mean number of finrays for each inch-group of fishes has also been calculated, and is to be found in the column to the right hand of the frequency data for males and females alike.

The results contained in this table are particularly interesting. If we neglect the values ascribed to the extreme inch-groups, viz., those containing 11- and 17-inch fish, which are naturally erratic on account of the small number of observations, we see that on the whole there is a distinct tendency for the percentage of high values to diminish with increased size of fish. The Irish results are clearer than those for the Channel in this respect, owing to the greater number of large Irish fish. I will, therefore, direct attention to them in the first place. We see, for example, that for Irish fish of 12 and 13 inches length, whether males or females, at least $40 \%$ possess more than 12 finrays; whereas for fishes above that size the percentage of high values (i.e., above 12 rays) never exceeds $33 \%$ and in most cases does not exceed $30 \%$. On the other hand, the percentage of low values (i.e., below 12 rays) does not exceed $22 \%$ for fishes of 12 and 13 inches, but is increased to $30 \%$ or more in the case of fishes of 15 and 16 inches in length. This general tendency is expressed fairly accurately by the mean values, which vary between $12 \cdot 24$ and $12 \cdot 35$ for the smaller fish (12 and 13 inches), and between 11.90 and 12.05 for the larger fish (15 and 16 inches).

We reach, accordingly, this general result, that, among Irish fish, whether males or females, the average number of finrays decreases as the length of the fish increases.

Of course, this generalisation only applies to fish within the sizelimits of the present investigation, i.e., to mackerel of marketable size, between 11 and 17 inches in length. I have not hitherto received any small first-year fish from Irish waters, and cannot, therefore, say at what stage the maximum number of finrays is present. Some remarks on 
this point in connection with yearling Plymouth fish will be found below.

A second conclusion is also forced upon us by a comparison of the figures on the left and right sides of the same Table (F), which deal with the frequency of the various values for males and females respectively. Subject to the same reservation in regard to the extreme size-groups, we may say that, for each size of fish, the table shows a perfect agreement between males and females in regard to the relative frequency of high and low values. When high values predominate among the males, they predominate also among the females of the same size; when the percentage of low values rises in one sex, it rises also in the other. There is accordingly a close agreement between the mean number of finrays in males and females of the same size.

In the series of size-groups of Irish fish, whether male or female, the first distinct fall in the mean number of finrays occurs in the group of 14-inch fish, in which there is a decrease of 0.25 for the males, and 0.29 for the females, as compared with the mean values for the corresponding groups of 13 -inch fish.

Unfortunately the group of 12 -inch Irish fish is inadequately represented, and when we pass to the Channel and North Sea fish, we see that the group of 14 -inch fish is there represented in the case of the males by only 26 fish, which is also insufficient to yield a reliable result. This is seen, for example, in the lack of correspondence between the means for the Channel males and females of this size, a feature which is still more noticeable for the 15 -inch fish, which are represented by only 6 specimens of each sex.

In order, therefore, to compare the Irish with the Channel results, it is necessary to enlarge the size-groups, and this I have done by dividing the whole set of fish into three, instead of eight, compartments according to the size of the fish.

These compartments are as follows :-
(1) 10, 11, and 12-inch fish.
(2) 13 and 14-inch fish.
(3) 15,16 , and 17 -inch fish.

As we have already seen that the mean values indicate pretty closely the changes which take place in the percentage distribution of high and low values, it will be unnecessary to recombine the percentage values in a separate table, although anyone desirous of checking these results can readily do so from the data given in Table F. I will give here merely the mean values for the three compartments already defined. 
TABLE VIII., showing mean number of first dorsal finrays for males and females of different sizes.

\begin{tabular}{|c|c|c|c|c|c|c|c|c|}
\hline \multirow{2}{*}{$\begin{array}{l}\text { Size of Fish } \\
\text { (inches). }\end{array}$} & \multicolumn{4}{|c|}{ Ireland. } & \multicolumn{4}{|c|}{ Channel and North Sea. } \\
\hline & No. & $\sigma^{\pi}$ & No. & $q$ & No. & 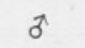 & No. & ㅇ \\
\hline 10,11 , and 12 . & 27 & $12 \cdot 33$ & 26 & $12 \cdot 31$ & 111 & $12 \cdot 21$ & 140 & $12 \cdot 31$ \\
\hline 13 and 14 & 107 & $12 \cdot 16$ & 83 & $12 \cdot 14$ & 105 & $12 \cdot 13$ & 128 & 12.02 \\
\hline 15,16 , and 17 . & 36 & $11 \cdot 92$ & 66 & $11 \cdot 94$ & 7 & $12 \cdot 00$ & 8 & 12.00 \\
\hline
\end{tabular}

This table shows two things :-

1. That a reduction in the number of recognisable finrays with increasing size is a general phenomenon, common to mackerel from Irish and English seas alike: and

2. That there are no sexual peculiarities at any size in regard to the number of finrays in the first dorsal fin.

The first of these conclusions is obvious enough. The second conclusion is founded on the practical identity of the mean values for Irish males and females at corresponding sizes, and on the inconsistency in kind of the differences which exist between the males and females of the Channel and North Sea. The mean for the females in the first compartment exceeds that for the males by $0 \cdot 10$, while in the second compartment the mean for the males exceeds that for the females by $0 \cdot 11$. Whatever may be the explanation of these deviations between the male and female values, it is clearly not due to the existence of any secondary sexual peculiarities in the number of finrays.

The questions naturally arise, at what period in the life of a mackerel does the process of reduction begin, and what is the cause of the reduction?

The first question can only be answered after the examination of large numbers of young mackerel. The material at my disposal is at present too limited for me to go minutely into the matter, but is sufficient to show that the reduction in the number of rays begins before the attainment of a length of 10 inches. The mean number of finrays in 127 Plymouth mackerel above $12 \frac{1}{2}$ inches in length is 12.02 ; the mean in 129 small mackerel from the same locality, all of which were below $10 \frac{1}{2}$ inches in length, is $12 \cdot 49$. The frequency of the different values is shown in the following table:- 
TABLE IX., showing frequency of finray numbers in small and large Plymouth fish, irrespective of sex.

Small fish = below $10 \frac{1}{2}$ inches; minimum size $5 \frac{1}{2}$ inches. Large fish $=$ above $12 \frac{1}{2}$ inches ; maximum size $15 \frac{3}{4}$ inches.

\begin{tabular}{|c|c|c|c|c|c|c|c|c|}
\hline \multirow{2}{*}{ Size. } & \multirow{2}{*}{$\begin{array}{l}\text { Number of } \\
\text { Fish. }\end{array}$} & \multicolumn{6}{|c|}{ Number of Finrays. } & \multirow{2}{*}{ Mean. } \\
\hline & & 10 & 11 & 12 & 13 & 14 & 15 & \\
\hline Small. & 129 & & 21 & 48 & 41 & 14 & 5 & 12.49 \\
\hline Large. & 127 & 8 & 24 & 62 & 25 & 7 & 1 & 12.02 \\
\hline Small. & $\%$ & & 16 & 37 & 32 & 11 & 4 & $12 \cdot 49$ \\
\hline Large. & $\%$ & 6 & 19 & 49 & 20 & 5 & 1 & 12.02 \\
\hline
\end{tabular}

As regards the cause of the reduction in the number of recognisable finrays, there are two possibilities, (1) the gradual absorption, and (2) the gradual concealment of the minute posterior rays.

I have been unable as yet to determine the extent to which actual absorption of the rays takes place, but I believe that some part of the reduction, if not the whole of it, is due to changes in the relation of the fin to the neighbouring tissues during growth of the fish. In an adult mackerel the first dorsal fin is lodged in a deep groove, within which it can be entirely depressed-an adaptation, without doubt, to habits of rapid locomotion, as this fin is never used for swimming, and would only be a hindrance if incapable of being bent back and tucked away within its socket; but in young fish up to 7 or 8 inches in length the groove is not yet formed. Consequently, in old mackerel the basal part of the fin is sunk beneath the general surface of the skin, while in young mackerel every part of the fin is freely exposed. The minute posterior rays do not protrude outside the groove in old fish, but are clearly visible in young fish. In these they require no preparation or dissection to be displayed; but in old fish the groove has to be carefully explored with a seeker, and often the lateral flaps of skin have to be cut away for the purpose, before the number of projecting rays can be accurately ascertained. This, of course, is a mere matter of care, which it is needless to say was invariably bestowed in the course of the investigation, the number of rays in this fin having been counted in each fish at least twice, and often four or five times, before being recorded. But a real difference between the two conditions consists in the fact that the posterior rays in large fish generally project less above the floor of the groove than do the corresponding rays of small fish, thus indicating in large fish a 
process of encroachment upon the lower part of the fin by the surrounding tissues. I fancy, therefore, that as the fish grows, this encroachment leads to the gradual covering up of the smallest rays altogether, which would sufficiently account for the observed reduction in the number of finrays as growth of the fish increases. As already remarked, I cannot yet say whether the spines are ever actually absorbed. From the nature of the case such a conclusion could only be derived from an extensive study of macerated specimens of different sizes, since mackerel will not live more than a few days in captivity, and it has not been possible to devote the necessary time to such an enquiry.

$\S 4$. Racial differences. Owing to the reduction of the number of finrays with growth of the fish, it is clearly impossible to use the data given in Table $\mathrm{E}$ as a basis for conclusions as to racial peculiarities, since no account has been taken in that table of growth-changes. If any racial peculiarities exist, they can only be determined by comparing fish of the same size from the different localities. Accordingly, as the various localities are most uniformly represented by 13 -inch fish (see Table I, p. 246), I have compared the mean numbers of finrays in local groups of fish of this size.

The results are as follows:-

\begin{tabular}{|c|c|c|c|c|c|c|c|c|}
\hline American . & & 33 & ish. & & & \multicolumn{3}{|c|}{ Mean number $=11.88$} \\
\hline North Sea. & & . 166 & , & & & $"$ & $"$ & $12 \cdot 14$ \\
\hline Plymouth. & & 64 & " & & ( & $"$ & $"$ & $12 \cdot 00$ \\
\hline Brest and Scilly & & 56 & 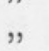 & & $\cdot$ & ", & " & $12 \cdot 16$ \\
\hline Kinsale . & & 49 & , & & • & " & $"$ & $12 \cdot 14$ \\
\hline Kerry & & 49 & , & • & - & , & , & $12 \cdot 33$ \\
\hline
\end{tabular}

The number of fish representing most of the localities is unfortunately too small to yield very accurate results, but the general trend of the differences is probably reliable. The American sample, as in other cases, yields one of the extreme values, in this case the lowest; and among European samples the Kerry and Channel values are widest apart, as was also the case in regard to the transverse bars (Table B) and intermediate spots (p. 266). The difference between the values for Plymouth and the North Sea is certainly rather large, as also is that between Kinsale and Kerry; but, in view of the small available numbers of fish of the proper size, I doubt whether any importance can be attached to these differences. A more reliable conclusion can probably be derived from the fact that the maximum value for the Channel and North Sea is no higher than the minimum value for the Irish coasts, and that Brest and Scilly yield a value which is intermediate between the two. 
This result is in complete agreement with the results already obtained in regard to the number of bars and the degree of spottiness.

That this result is not accidental, but is founded on real differences in the degree of evolution of the different races of fish will be made clear in the next section.

\section{Correlation between Spottiness and Number of Finrays.}

We have already seen that the presence of intermediate spots among the transverse bars indicates a departure from the primitive arrangement of the bars, which coincided with the lines of the myotomes or musclesegments. Increased spottiness accordingly indicates an increased departure from the primitive condition. We have also seen that the common mackerel belongs to the most primitive group of species of the genus Scomber so far as its markings are concerned. I have, moreover, briefly referred to the fact that the number of finrays in the first dorsal fin is higher in the common mackerel than in any other species of the genus Scomber. As the number of finrays has also been shown to be higher in young than in old mackerel, it is certain that, for the race as for the individual, a high number of finrays is the primitive condition for Scombroid fishes.

Accordingly, as increase in spottiness and reduction of finrays are equally departures from the primitive condition, we might expect to find a correlation between these two characters in well-defined races of mackerel; and if this correlation occurs in representative samples of fishes from different localities, it furnishes the strongest possible argument for their racial distinctness.

Such a correlation undoubtedly exists, as is shown in the following table, which gives for each group of fishes the indices of spottiness already ascertained (p. 267) side by side with the mean number of finrays in the first dorsal fin, as determined in fish of 13 inches length. Although an extensive examination of the variation of the Spanish mackerel, Scomber colias, has not yet been made, its spottiness is so marked, and the number of its finrays is so decidedly reduced, that I have no hesitation in placing it here as a type of extreme departure from the primitive Scombroid condition.

\begin{tabular}{|c|c|c|c|}
\hline $\operatorname{Rac}$ & $\begin{array}{l}\text { Percentage } \\
\text { of Spotty } \\
\text { Fish. }\end{array}$ & $\begin{array}{l}\text { No. of Spots } \\
\text { per } 100 \\
\text { Fish. }\end{array}$ & $\begin{array}{c}\text { Mean No. of } \\
\text { Finrays } \\
\text { (13 inches). }\end{array}$ \\
\hline & $100 \%(?)$ & $500(?)$ & $7-10$ \\
\hline
\end{tabular}

Scomber colias

Sc. scomber

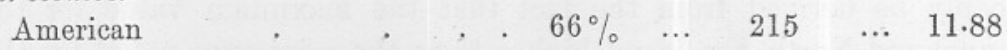

$\left\{\begin{array}{lllllll}\text { North Sea and English Channel } & . & 21 \% & \ldots & 37 & \ldots & 12.10\end{array}\right.$

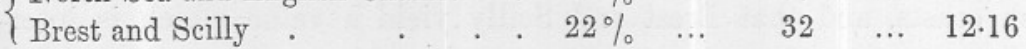

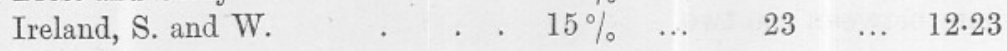


It would be difficult to find a more convincing demonstration than this table affords as to the existence of local races of the common mackerel; and when it is remembered that the variation in the number of transverse bars led to a precisely similar grouping of the local consignments (p. 255), there can remain, I think, no doubt as to the general accuracy of the conclusions which are drawn in this report concerning the races of the mackerel.

The contrast between the Irish and English races of mackerel is sufficiently clear from the figures in the table, but it becomes still more distinct if we contrast the English race with the West coast stock of the Irish race, since the Kinsale fish occupy an intermediate position between the Kerry fish and the English race in respect of both characters. The following are the distinctive characters of the two stocks of the Irish race:-

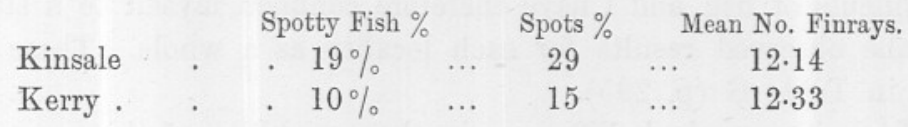

In respect both of spottiness and number of finrays, the Kinsale stock approaches the Channel race more closely than it does the Kerry stock, although intermediate between the two. In respect of the number of transverse bars it also holds an intermediate position, as already shown, but comes nearer the Kerry stock than the Channel race. The facts, therefore, demand the subdivision of the Irish race into West coast and South coast stocks.

On the other hand, it can be seen from the data already provided that no similar differences separate the North Sea from the Plymouth fish, the racial identity of which must accordingly be regarded as absolute.

The combined Brest and Scilly data approximate throughout to those for the North Sea and Channel, although they show a slight approach under each character towards the Irish, and particularly the Kinsale, values. In regard to the number of transverse bars, the high average of the Brest and Scilly fish shown in Table C would also appear to indicate an incipient racial divergence between the fish of the Channel proper and those which in summer haunt the mouth of the Channel west of a line from Mounts Bay to Brittany.

If this is so, it is a matter of the greatest importance, since it would necessitate the conclusion that the winter quarters of the North Sea and Channel fish are to be found in the Channel itself, and not to the west of it. This conclusion is by no means improbable, and would harmonize well with the peculiarities of the Plymonth winter fishery; but I cannot regard the evidence of the relatively small samples of 
Brest and Scilly fish, or that of the partial series of transverse bars (Table C), as by any means decisive. I hope to re-examine these details by means of larger samples during the coming year.

\section{Second Dorsal Fin.}

The variation in the number of finrays in the second dorsal fin is much slighter than in the case of the first dorsal. The extreme range of variation is from 9 to 15 , i.e., 7 rays; but the two extreme values on each side of the mode (i.e., 9, 10, 14, and 15) occur very rarely, so that the range of variation scarcely covers more than 3 rays, viz., from 11 to 13 .

Owing to the limited variability of the organ, no useful purpose would be served by publishing the separate data for the various consignments of fish, and I have therefore confined myself to a statement of the observed results for each locality as a whole. These are set out in Table G (p. 295).

There is a marked difference in the variability of this organ in the American fish as compared with the samples of European fish; for, whereas 12 rays occur in from 82 to $85 \%$ of the European fish, they are found in only $63 \%$ of the American, and the frequency of each of the remaining values is from twice to three times as great for the American fish as for the European. The mean value for the American sample is also considerably lower than for any European sample examined. The highest mean is that for the North Sea (11.950), and the lowest that for Kinsale (11.927), the difference between the two being 0.023 . But the difference between the American mean and the nearest European mean is much greater than this, being 0.077.

The differences between the European samples are exceedingly slight, but attention may be drawn to the fact that the localities which provide the highest and lowest mean-values are geographically remote, viz., the North Sea and Kinsale.

The only satisfactory way of comparing values which present such slight local differences in the frequency of their occurrence, will be to combine the values above and below the mode (12) into two compartments of high and low value respectively, as below. 
TABLE X., showing frequency of High and Low Values of the Second Dorsal Fin.

(Percentages.)

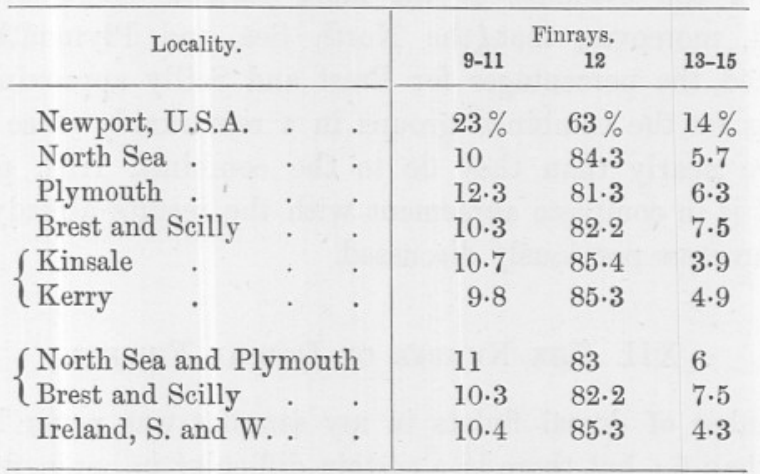

Undoubtedly the two groups which agree most closely according to the above table are those from Kinsale and Kerry. For these groups the frequency of the mode is the highest recorded, and is practically identical in the two cases $(85.3$ and $85.4 \%$ ). The two lowest frequencies of the high values (3.9 and $4.9 \%$ ) are also found in the same groups.

The figures do not appear to justify any further amalgamation of the groups; but it is worth noticing that the North Sea group approximates closer in its values to the Irish samples than does either of the others-a feature which is again exhibited with respect to the dorsal finlets.

We have already seen that, in respect to spottiness and the number of finrays in the first dorsal fin, the Irish fish approach most nearly to the theoretically primitive condition. Now the primitive number of rays in the second dorsal fin would appear almost certainly to have been 12, partly on account of the high frequency of this number throughout the samples, and partly on account of the fact, which is established below, that when this number is exceeded, the number of finlets tends to be reduced, and when the number of rays is reduced below 12, the number of finlets tends to be increased. This correlation implies a primitive constancy in the number of rays in the posterior dorsal fin of the ancestral mackerel prior to its subdivision into second dorsal and finlets. The total number of rays in the ancestral continuous fin was probably 17 , which became subdivided into 12 rays for the primitive second dorsal fin and 5 rays for the finlets. If this view is correct, it is to be remarked that in the high frequency of the modal number of rays in the second dorsal fin, the Irish fish again display 
their primitive character. On this account, in spite of the slender basis for drawing racial distinctions from the variation of the present character, I think it will be conceded that, so far as any conclusions at all are permissible, they confirm the inferences which have already been drawn from the evidence of the more variable characters. It will be noticed, moreover, that/the North Sea and Plymouth data are amalgamated, the percentages for Brest and Scilly approximate to the percentages for the combined groups in a remarkably close manner,much more nearly than they do to the combined Irish percentages. This result is in complete agreement with the results already described for the characters previously discussed.

\section{The Number of Dorsal Finlets.}

The number of dorsal finlets in my samples was never less than 4 nor more than 6 ; but there is a certain difficulty in enumerating them, owing to the fact that the last ray of the second dorsal fin is sometimes imperfectly separated off as an accessory, or incipient, finlet. As the finlets and second dorsal fin are both modifications of a primitively continuous fin (such as that which exists in Caranx trachurus, the borse-mackerel, and its allies), it is desirable to include these incipient finlets in an account of the variability of the number of finlets. They have been included in the account of the second dorsal fin as a matter of course, each incipient finlet counting as one dorsal ray; but in the present case, in order to reduce their value as compared with the fully constituted and independent finlets, I have regarded them as halffinlets. Thus, a fish which has 4 true finlets and one incipient finlet has been recorded as having $4 \frac{1}{2}$ finlets.

The observed frequency of the different possibilities is recorded in Table H (p. 295).

The normal or modal number is, of course, 5. In the European samples this number occurs in from 92 to $94 \%$ of the fish, but the American race of mackerel is again distinguished from the European samples by its greater variability in regard to this character, the modal number being found in only $79 \%$ of the observed cases. In only $2 \%$ of the cases was the number reduced below 5 , viz., $4 \frac{1}{2}$, but no specimen was seen with only 4 finlets. On the other hand, $19 \%$ had more than 5 finlets, viz., $12 \%$ with $5 \frac{1}{2}$ finlets, and $7 \%$ with 6 .

The slight variability of the European fish in regard to this character renders necessary the same treatment as was applied in the case of the second dorsal fin, and I have therefore merged into a single compartment the cases showing less than 5 typical finlets, and into another compartment the cases with more than 5 typical finlets. 


\section{TABLE XI., showing frequency of High and Low Numbers of Dorsal Finlets.}

(Percentages.)

\begin{tabular}{|c|c|c|c|c|}
\hline \multicolumn{2}{|l|}{ Locality. } & \multicolumn{3}{|c|}{ Dorsal Finlets. } \\
\hline Newport, U.S.A. & . & $2 \%$ & $79 \%$ & $19 \%$ \\
\hline Nort & . & 2 & 94.5 & $3 \cdot 5$ \\
\hline $\int$ Plymouth. & . & $3 \cdot 3$ & $92 \cdot 3$ & $4 \cdot 3$ \\
\hline Brest and Scilly & . & 4 & 93 & 3 \\
\hline \{ Kinsale & . & $2 \cdot 4$ & $94 \cdot 4$ & $3 \cdot 2$ \\
\hline C Kerry & & 2 & $94 \cdot 3$ & $3 \cdot 7$ \\
\hline North & mouth & $2 \cdot 6$ & $93 \cdot 6$ & $3 \cdot 8$ \\
\hline Brest and Scilly & & 4 & 93 & 3 \\
\hline Ireland, S. and W & & $2 \cdot 3$ & $94 \cdot 4$ & $3 \cdot 3$ \\
\hline
\end{tabular}

This table is, on the whole, similar in its general features to Table X., showing the variation of the second dorsal finrays. A very elose affinity is revealed between Kinsale and Kerry, and again between Plymouth and the combined samples from Brest and Scilly, but the North Sea values, which merely approximated to the Irish values in the case of the dorsal fin, now entirely agree with them.

We again see that the Irish group is characterised by the high frequency of the normal number of finlets, or, as we may say, by its high normality.

In revealing the close affinity between the Kinsale and Kerry groups, and between the Plymouth group and the combined Brest and Scilly samples, this table furnishes a confirmation of what has previously been urged with regard to these points. The difference between the North Sea and Channel groups, although foreshadowed in the case of the second dorsal fin, is novel, and possibly significant; but in the next section it is shown that the variability of these organs is too slight to admit of any inferences being safely drawn as to the affinity between the various local groups of fish. The maximum number representing any one locality is only 410 , while the deviations from the normal condition do not exceed $8 \%$ for any of the British localities in the case of the dorsal finlets.

\section{Correlation between Variations of Second Dorsal Fin and Number of Dorsal Finlets.}

During the examination of the mackerel received, I frequently had occasion to notice that a marked degree of correlation exists between the number of finrays in the second dorsal fin and the number of finlets. I am not qualified at present to discuss the facts from a mathematical 
standpoint, but the existence of the correlation can readily be demonstrated.

As the variation of both characters is most marked in the American sample, I have analysed the data provided by it in the following manner :-

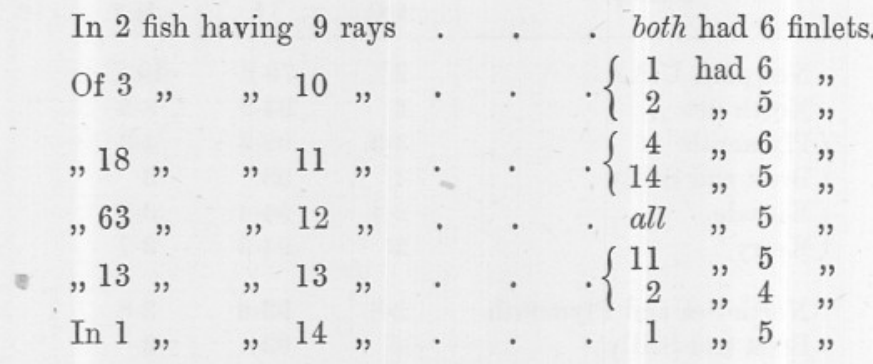

These figures show (1st) that the normal or modal number of finrays (12) is constantly associated with the normal or modal number of finlets (5); (2nd) that when the number of finrays is below 12 , the variation in the number of finlets is confined to deviations above the mode; and ( $3 \mathrm{rd}$ ) that when the number of finrays is above 12 , the deviations from the modal number of finlets are exclusively below the mode.

This relation can be shown still more clearly as follows :-

$$
\begin{aligned}
& \text { Of } 7 \text { fish with } 6 \text { finlets }\left\{\begin{array}{lll}
2 \text { had } 9 \text { rays. } \\
1, & 10, \\
4 & , & 11,
\end{array}\right.
\end{aligned}
$$

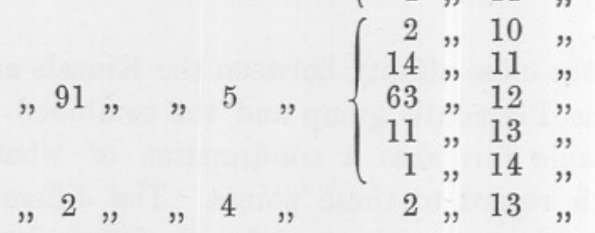

These figures show (1st) that the normal number of finlets (5) is associated with a wide range of variation in regard to the number of rays in the second dorsal fin (from 10 to 14), (2nd) that when the number of finlets is above 5 , the number of rays is constantly below 12 ; and (3rd) that when the number of finlets is below 5 , the number of rays is constantly above 12 .

This correlation is also exhibited by the mean values of each character for the American sample, the mean number of finrays (11.850) being the lowest observed, and the mean number of finlets $(5 \cdot 120)$ being the highest observed.

If the mean values for the various British localities are correct, they ought to exhibit a similar correlation in regard to these characters; but, as will be seen from the following table, such a correlation between the local means does not exist. The localities are grouped in order of 
magnitude of the mean numbers of dorsal finlets; the inverse order of magnitude for the second dorsal values is given in brackets.

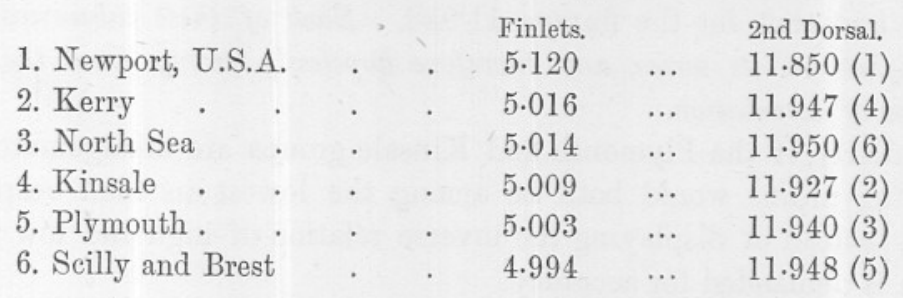

It will be seen that there is a conspicuous lack of correlation between the mean values for the various local groups of European fish. Kerry and the North Sea, which have the highest average number of finlets, ought to have the lowest number of dorsal rays, instead of which these values are among the highest observed. On the other hand, the combined Brest and Scilly values occupy approximately their correct positions in the sequence.

It is clear, therefore, that the means cannot be regarded as correctly representative of the local groups of fish, and that no racial affinities or differences can be based on the figures as they stand. In view of the indubitable correlation between the two characters under discussion, I am inclined to attribute the inaccuracy of the means to the slight amount of variation in these characters among European fish, which renders necessary a much larger number of data than those at my disposal. A sufficient increase in the number of observations for each region would render the means more truly representative, and ought to reveal the correlation that must be exhibited before the values can be regarded as reliable.

Indirectly this explanation indeed can be shown to be correct by amalgamating those groups which we have already seen upon other grounds to be closely related. The order is the same as in the preceding list.

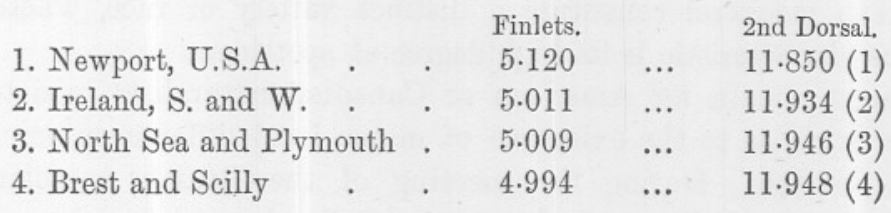

This table shows that when the local groups of fish are amalgamated in the manner described, the means for finlets and second dorsal fin are distributed in the order demanded by the correlation of the two characters.

This result is not obtainable by any other mode of amalgamation. Thus, if the Kerry and North Sea groups are merged together, on the 
ground of the close resemblance they exhibit in regard to the high mean number of finlets, the resulting mean for the finlets becomes 5.015, and that for the finrays 11.948. Each of these values would be the highest in its series, and therefore hopelessly wrong from the point of view of correlation.

Similarly, if the Plymouth and Kinsale groups are amalgamated, the resulting means would both be among the lowest in their respective series, instead of displaying the inverse relation of high and low values which is demanded for accuracy.

I conclude from these facts that the grouping which fulfils the correlation test is the correct one; and, as this grouping is identical with that demanded by the variation of all the other characters examined, it would appear to rest upon the firm basis of real genetic affinity and racial differences.

\section{Summary of Evidence concerning the Races of the} Mackerel.

\section{§1. American Mackerel.}

The American mackerel have been shown in this report to differ very considerably from all samples of European mackerel examined.

The difference is exhibited in regard to every character the variation of which has been determined, and in every respect the American fish hold an extreme position among my samples. Thus the highest average is yielded by the American sample in regard to the following characters: (1) the number of transverse bars, (2) the number of spotty fish, (3) the number of spots per hundred fish, and (4) the number of dorsal finlets; whilst the lowest average is yielded by it in regard to the number of finrays in (1) the first dorsal, and (2) the second dorsal fin.

There can be no doubt as to the significance of these facts. The American mackerel constitute a distinct variety or race, whose most obvious characteristic is its high degree of spottiness.

It must remain for American or Canadian naturalists to determine the question as to the existence of minor local differences among the American fish. During the meeting of the British Association at Toronto last year, I examined a dozen mackerel which had been caught in the Gulf of St. Lawrence; and, although this number is insufficient to determine the existence of minute racial differences, I may state that it was the examination of these fish which first revealed to me the marked spottiness of the mackerel of the western shores of the Atlantic. In this respect, therefore, I have no doubt of the close agreement between the mackerel of Canadian and American waters. 


\section{§ 2. European Mackerel.}

A subdivision of the mackerel which frequent the British coasts into two principal races, an Irish race and a race frequenting the English Channel and North Sea, appears to be demanded by the following facts which have been elucidated by my researches :-

(1) The identity of the Plymouth and North Sea fish, and the close agreement between the Kinsale and Kerry fish in regard to the variation in number of the transverse bars, and the emphatic difference between the two former and the two latter groups in regard to the same character;

(2) The close agreement between the Plymouth and North Sea fish in regard to the frequency of intermediate spots among the bars, and the emphatic difference between either of these groups and the Kerry fish in regard to the same character;

(3) The correlation of a relatively low average number of first dorsal finrays with a relatively high degree of spottiness in North Sea and Channel fish, and the correlation of the highest observed average number of finrays with the lowest observed degree of spottiness in the Irish fish. These correlated differences could not be expected to occur except in races of fish which had diverged to a different degree from the primitive condition;

(4) The correlated nature of the differences between the same two groups in regard to the-number of second dorsal finrays and dorsal finlets.

The discrimination of these races has been made exclusively on the ground of structural differences and resemblances between the fish coming from a number of chosen localities. If the differences revealed by the present investigation should appear to some to be too small to be significant, it should be remembered that large differences could not in any case be expected to occur between the mackerel of any two regions in British seas, partly because of the relative smallness of the total area and the possibility of free intercourse between its different waters, and partly because of the known activity and wandering tendencies of the adult mackerel, in addition to its production of freely floating eggs. If, on the other hand, the differences should be regarded by others as accidental, this idea may be negatived at once by the general conformity of the results obtained for different characters, and by the important fact that those local groups which are shown to resemble one another most closely are exactly those which might have been expected to do so from geographical considerations. If there are no valid differences between any of the British groups of mackerel, it is in the highest degree improbable, when the number of 
observations is taken into account, that the data accumulated for North Sea and Plymouth fish should coincide so closely as they do, and differ to so considerable an extent from the data determined for the fish from Kerry.

Nevertheless, although certain differences between the Irish fish and those from the Channel and North Sea must, I think, be conceded, it would be a serious error to conclude that the division between these two races of mackerel is hard and fast. I have shown that the Kinsale fish are distinctly intermediate in character between the fish from the west coast of Ireland and those of the Channel in regard to the following features:-(1) number of transverse bars, (2) spottiness, and (3) number of first dorsal finrays. I have also shown that the mackerel caught off Brest and Scilly, though closely related to the Channel fish as a whole, also betray a certain approximation towards the Irish, especially the Kinsale, values in regard to the same characters; and, although the number of fish representing this region is relatively small, I see no reason for doubting that the consensus of evidence on this point is of some significance. These two intermediate cases, therefore, prevent the establishment of any rigid line of separation between the Irish and the Channel races; but they at the same time confirm in a most emphatic manner the one paramount conclusion of the whole inquiry, viz., that the mackerel which frequent British waters are not exactly alike in all localities, but possess certain average peculiarities which distinguish one local race from another. These peculiarities are greatest between the races of localities which are geographically remote, and least between those which occupy areas that are geographically contiguous. Between the mackerel of the North Sea and English Channel there are no differences at all; but the Irish race is distinctly divisible into two stocks, one of which is restricted to the west coast, the other to the south. A considerable amount of mixture takes place between the southern Irish stock and the fish which frequent the mouth of the English Channel. The western Irish stock represents more closely than any other race the primitive type of mackerel, from which all, whether British or American, have been derived.

\section{The Migrations of the Mackerel.}

The establishment of geographical or local races of the mackerel settles a number of disputed points concerning the migrations of this fish. The theory of long migrations must be altogether given up. The mackerel certainly does not cross the Atlantic; the marked difference between American and European samples shows that at the present period of the earth's history there is no mixture between the two races. 
Moreover, in view of the difference between Irish and Channel fish, it can no longer be maintained that the mackerel of these regions wander far in winter from their summer haunts. Each race of fish must possess its own winter habitat, and this must be situated close to the region where the fish make their first appearance in the spring. Indeed, the only migrations which can, for the most part, be conceded, are migrations from shallow to deeper water off the same coasts. The one exception to this rule concerns the North Sea fish. The racial identity of these fish with those of the Channel proper furnishes a conclusive proof of the accuracy of the view that the North Sea fish are derived from the English Channel in the spring, and return to it in the autumn, thus ensuring a complete mixture between the two groups during the winter period. By North Sea fish, however, are meant merely the fish which are taken off the east coast of England from Yarmouth southwards. How far to the northwards the spring migration extends must be settled by further investigation.

The relation between the autumn and spring fish of any locality is also elucidated by the same results. No racial differences between autumn and spring fish have been revealed by my inquiries for any locality which has been represented by samples taken at both periods; and the existence of differences between the fish of different localities renders it practically certain that each locality is frequented by one race only, viz., the race peculiar to the locality. So far as the Irish fish are concerned, the minor racial differences established between the fish of Kinsale and Kerry prevent a special pronouncement upon this matter on the present occasion, since the Kerry fish were exclusively spring fish, and the Kinsale fish almost entirely autumn fish. The evidence, so far as it goes, points to the conclusion that on the Irish coast the small autumn mackerel are young fish which will to a large extent form part of the breeding shoals in the following spring.

This matter, however, is being further investigated, and the same material will furnish a means of testing the accuracy of the conclusions which have here been submitted concerning the characters of the local races.

In conclusion, I may draw attention to the relation of the local races to the conformation of the sea-bed, which appears to me to be of considerable importance in any attempt to delimit the area normally frequented by each race. If reference is made to a properly contoured chart-e.g., the charts of the fishing grounds in Cunningham's Marketable Fishes of the British Islands (Macmillan, 1896)-it will be seen that the mouth of the English Channel coincides with the 50-fathom line, that the same line bounds a large plateau of ground off the south coast of Ireland, but that off the west coast of Ireland it runs close 
to the coast-line. A moderately deep gully of more than 50 fathoms depth separates English from Irish territory.

Accordingly our division of British mackerel into an Irish and a Channel race coincides with the geographical division of the sea-bed by the 50-fathom gully which runs up St. George's Channel.

On the other hand, the 100 -fathom line approaches the coast only off the south-west coast of Ireland and separates a considerable plateau of ground off the west coast of Ireland from the great quadrangular plateau which lies to the south of Ireland, and the southern boundary of which coincides with the latitude of Ushant.

Deeper contour lines, up to 1000 fathoms, leave the boundary of the southern plateau practically unaffected, but considerably increase the area of that off the west coast of Ireland, which at 200 fathoms includes the Porcupine Bank, a distance of 250 miles from the mainland. On the other hand, the study of deeper contour lines renders still more evident the geographical distinctness of the two plateaux, which are connected merely by a narrow shelf off the south-west coast of Kerry, 50 miles wide at 100 fathoms, and only 120 miles wide at 1000 fathoms. Thus the separation of the Irish race into a west coast and south coast stock coincides with the division of the Irish submarine plateau into a western and a southern portion by the deep 1000 -fathom rift which has been described. As these banks probably form the winter quarters of the mackerel of the adjoining coasts, we can understand how the segregation 'of the Irish stocks has been induced, and how a certain amount of mixture between the Kinsale stock and the Channel race has taken place. The southern Irish stock is more closely related to the western Irish stock than to the Channel race on account of its proximity to the former during the breeding season. But it approaches the Channel race in character because it shares the same submarine plateau for its winter quarters; and, although this area is too large to bring about complete mixture of the two races, it is not large enough to prevent a certain amount of mixture from taking place. The annual amount probably depends upon the severity of the winter season, which determines the extent and depth to which the fish retire from the shore. 
Table A. Size of Fish (inches).

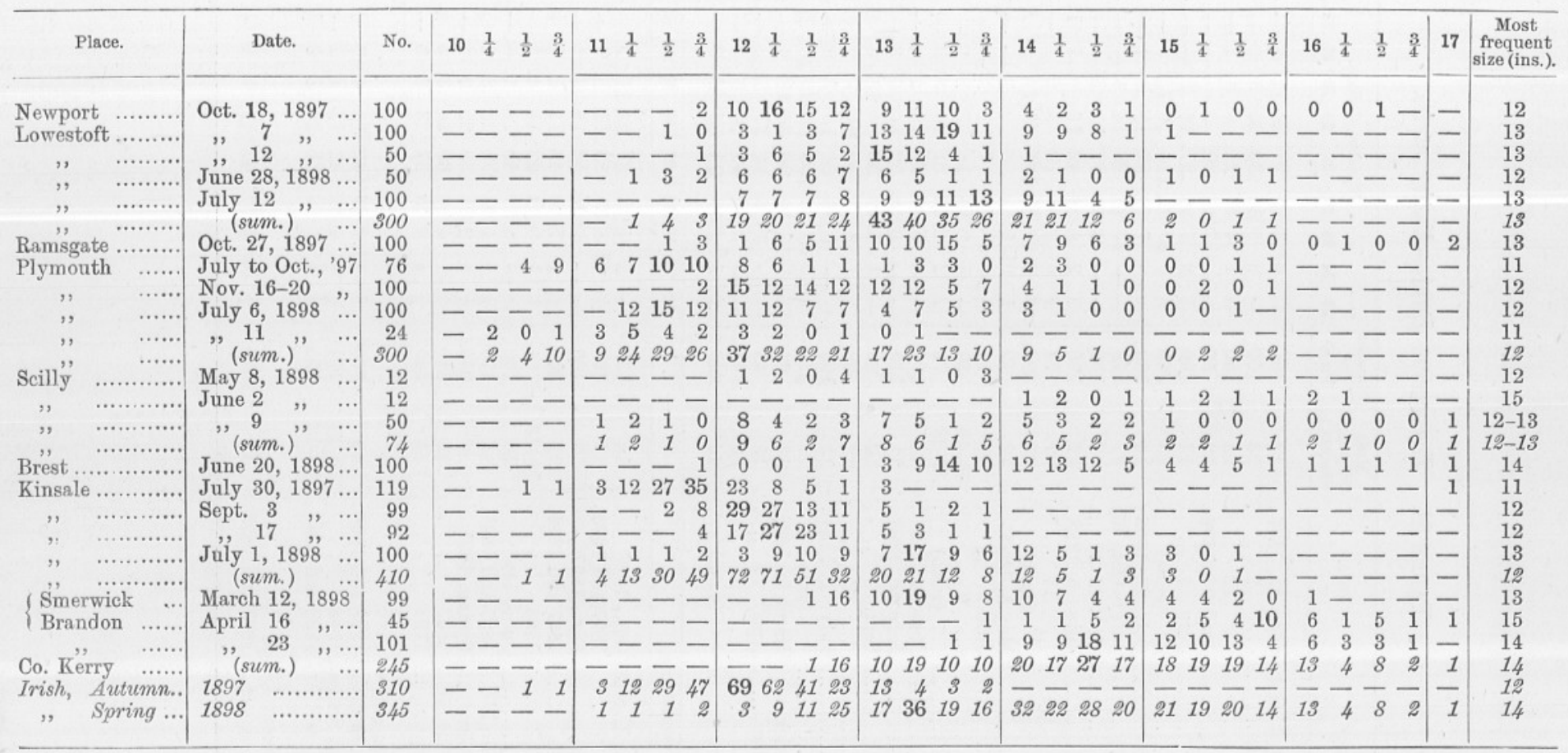


TABLE B. Transverse Bars-Entire series.

\begin{tabular}{|c|c|c|c|c|c|c|c|c|c|c|c|c|c|c|c|}
\hline \multirow{2}{*}{ Place. } & \multirow{2}{*}{ Date. } & \multirow{2}{*}{$\begin{array}{c}\text { Most } \\
\text { frequent } \\
\text { size(ins.). }\end{array}$} & \multirow{2}{*}{$\begin{array}{c}\text { Number } \\
\text { of } \\
\text { Fish. }\end{array}$} & \multicolumn{11}{|c|}{ Number of Bars } & \multirow[t]{2}{*}{ Mean. } \\
\hline & & & & 23 & 24 & 25 & 26 & 27 & 28 & 29 & 30 & 31 & 32 & 33 & \\
\hline Newport, U.S.A. & \multirow{6}{*}{ 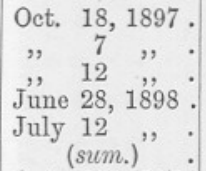 } & 12 & 100 & \multicolumn{2}{|r|}{2} & & 413 & 337 & 28 & 11 & \multirow{2}{*}{$\begin{array}{l}5 \\
2\end{array}$} & \multirow[t]{2}{*}{ - } & \multirow{2}{*}{\multicolumn{2}{|c|}{--}} & \multirow{2}{*}{$\begin{array}{l}27 \cdot 38 \\
26 \cdot 90\end{array}$} \\
\hline estoft. & & 13 & 100 & - & 2 & 5 & 30 & 36 & 20 & 5 & & & & - & \\
\hline ", . & & 13 & 50 & - & 1 & 4 & 11 & 21 & 8 & 4 & 1 & - & - & - & 94 \\
\hline , & & 12 & 50 & - & - & 7 & 17 & 20 & 6 & - & - & - & - & - & $\cdot 50$ \\
\hline ," & & 13 & 10 & 1 & 2 & 7 & 36 & 37 & 12 & 5 & - & 一 & - & - & $\cdot 62$ \\
\hline ate & & 1 & & 1 & 5 & 23 & 94 & 114 & 46 & 14 & 3 & & - & - & $2 t$ \\
\hline $\begin{array}{l}\text { fate. } \\
\text { uth. }\end{array}$ & Oct. 27, 1897 . & & 1 & - & - & 7 & 22 & 52 & 15 & 3 & 1 & - & - & - & \\
\hline h. & $\begin{array}{l}\text { July to Oet., } 97 . \\
\text { Nov. } 16-20\end{array}$ & 1 & & - & - & 10 & 20 & 28 & 14 & 4 & - & - & - & - & 2 \\
\hline, & July 6,1898 . & & & $\overline{1}$ & $\overline{2}$ & 4 & 35 & 47 & 11 & 3 & - & $\overline{1}$ & $\overline{0}$ & - & 2 \\
\hline & , 11, & & & 1 & $\begin{array}{l}2 \\
0\end{array}$ & 4 & 28 & 42 & 16 & 4 & 1 & 1 & 0 & 1 & $26 \cdot 91$ \\
\hline & (sum.) & 12 & 300 & $\begin{array}{l}1 \\
2\end{array}$ & $\begin{array}{l}0 \\
2\end{array}$ & $\begin{array}{r}2 \\
20\end{array}$ & $\begin{array}{r}7 \\
90\end{array}$ & $\begin{array}{r}10 \\
127\end{array}$ & $\begin{array}{r}3 \\
44\end{array}$ & $\begin{array}{r}0 \\
11\end{array}$ & $\begin{array}{l}1 \\
2\end{array}$ & $\overline{1}$ & $\overline{0}$ & -1 & \\
\hline Scilly & May 8, 1898 & 12 & 12 & 1 & $\tilde{0}$ & 0 & 2 & 6 & $\begin{array}{r}44 \\
2\end{array}$ & $\begin{array}{r}11 \\
1\end{array}$ & - & - & - & $\underline{-1}$ & b \\
\hline ," & June 2 & 15 & 12 & - & - & 一 & 3 & 7 & 1 & 1 & - & - & - & - & \\
\hline$"$ & , 9 " & $12-13$ & 50 & - & 1 & 2 & 19 & 18 & 7 & 1 & 2 & - & - & - & $26 \cdot 78$ \\
\hline res & (sum.) & $12-13$ & 74 & 1 & 1 & 2 & 24 & 31 & 10 & 3 & 2 & - & - & - & 2 \\
\hline Ginsale . & June 20, 1898 . & 14 & 100 & - & - & 5 & 32 & 40 & 19 & 4 & - & - & - & - & 2 \\
\hline sinsale & July 30,1897 . & 1 & 1 & - & $\overline{1}$ & 6 & 18 & 52 & 34 & 6 & 3 & - & - & - & $27 \cdot 2$ \\
\hline , & Sept. $3 \quad, \quad$. & 1 & s & $\overline{1}$ & 1 & 5 & 22 & 30 & 24 & 13 & 3 & 1 & $\overline{1}$ & 一 & 2 \\
\hline , & July $1,1898^{\circ}$. & $\begin{array}{l}12 \\
13\end{array}$ & $\begin{array}{r}92 \\
100\end{array}$ & 1 & 1 & $\begin{array}{l}2 \\
5\end{array}$ & $\begin{array}{l}17 \\
36\end{array}$ & $\begin{array}{l}40 \\
34\end{array}$ & $\begin{array}{l}21 \\
16\end{array}$ & 7 & $\begin{array}{l}2 \\
2\end{array}$ & $\underline{0}$ & 1. & - & \\
\hline & (sum.) & 12 & 410 & 1 & 2 & 18 & 93 & 156 & 95 & $S S$. & 10 & 1 & 1 & - & $27 \cdot 1$ \\
\hline $\begin{array}{l}\text { Smerwick ... } \\
\text { Brandon ... }\end{array}$ & March 12, 1898. & 13 & 99 & 1 & 1 & I & 19 & 36 & 26 & 11 & 4 & - & - & - & $27 \cdot 3$ \\
\hline Brandon $\ldots$ & April 16, , . & 15 & 45 & - & - & 1 & 6 & 14 & 17 & 5 & 2 & - & - & - & $27 \cdot 5$ \\
\hline o. K’erry. & $3 u n$ & 14 & 101 & -1 & - & 3 & 25 & 44 & 20 & 6 & 3 & & - & - & $27 \cdot 1$ \\
\hline & & & & & & & & & & & & & & & \\
\hline Perc & . & . & . & 23 & 24 & 25 & 526 & 27 & 28 & 29 & 30 & 31 & 32 & 33 & \\
\hline Tewport, U.S.A. & t., & 1 & & - & 2 & 4 & 13 & 7 & 28 & 11 & 5 & - & - & - & \\
\hline toft & 8. & 1 & & $\frac{1}{3}$ & $1 \frac{2}{3}$ & $\frac{2}{3} 8$ & 31 & 8 & 15 & 5 & 1 & - & - & - & 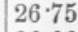 \\
\hline rate. & t., 1 & 1 & & - & - & 7 & 22 & 2 & 15 & 3 & 1 & - & - & -1 & : \\
\hline ut & 7 and 1 & & 3 & $\frac{1}{3}$ & 1 & 7 & 30 & 2 & 14 & 4 & 1 & $\frac{1}{3}$ & 0 & $\frac{1}{3}$ & ; \\
\hline lly & & 12 & & 1 & 1 & $\begin{array}{l}3 \\
5\end{array}$ & 32 & 2 & 14 & 4 & 3 & - & - & - & 2 \\
\hline rish : K & 7 and 1 & 1 & & $\overline{\frac{1}{1}}$ & $\overline{\frac{1}{2}}$ & $\begin{array}{l}5 \\
4\end{array}$ & $\begin{array}{l}32 \\
23\end{array}$ & $\begin{array}{l}40 \\
38\end{array}$ & $\begin{array}{l}19 \\
23\end{array}$ & $\begin{array}{l}4 \\
8\end{array}$ & $\overline{3}$ & $\sqrt{\frac{1}{4}}$ & $\overline{1}$ & - & \\
\hline , $\mathrm{K}$ & Spring, 1898 & 1 & & $\frac{1}{2}$ & $\frac{1}{2}$ & 2 & 21 & 38 & 25 & 9 & 4 & - & - & - & $27 \cdot 27$ \\
\hline$", \quad \mathrm{~A}$ & . & 1 & & $\frac{1}{3}$ & 1 & 4 & 18 & 39 & 26 & 8 & 3 & $\frac{1}{3}$ & $\frac{1}{3}$ & - & $27 \cdot 2$ \\
\hline Sprin & 1 & & 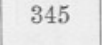 & $\frac{1}{2}$ & $\frac{1}{2}$ & 3 & 25 & 37 & 23 & 8 & 3 & & & - & $27 \cdot 1$ \\
\hline North Se & & & & & & & & & & & & & & & \\
\hline an & 1897 al & & & $\frac{3}{7}$ & 1 & 7 & $\begin{array}{l}29 \\
39\end{array}$ & 42 & 1 & 4 & 1 & $\frac{1}{7}$ & - & $\frac{1}{7}$ & $\begin{array}{l}26.79 \\
26.84\end{array}$ \\
\hline Irish, $\mathbf{S}$. and W. & 1897 and $i$ & $12-13$ & $\begin{array}{l}174 \\
65\end{array}$ & $\frac{\frac{1}{2}}{\frac{1}{3}}$ & $\frac{1}{2}$ & $\begin{array}{l}4 \\
4\end{array}$ & $\begin{array}{l}32 \\
22\end{array}$ & $\begin{array}{l}41 \\
38\end{array}$ & $\begin{array}{l}17 \\
24\end{array}$ & $\begin{array}{l}4 \\
8\end{array}$ & $\begin{array}{l}1 \\
3\end{array}$ & $\overline{1}$ & & & $\begin{array}{l}26 \cdot 8 \\
27 \cdot 2\end{array}$ \\
\hline Total, ex & & & & & & & & & & & & & & & \\
\hline New] & 1897 and 1 & 13 & 1529 & $\frac{1}{3}$ & $\frac{1}{2}$ & 5 & 27 & 41 & 19 & 5 & 2 & $\frac{1}{8}$ & ${ }^{-1} 0$ & $\frac{1}{10}$ & $26 \cdot 97$ \\
\hline
\end{tabular}


TABLE C. Transverse Bars which cross or touch the Lateral Line.

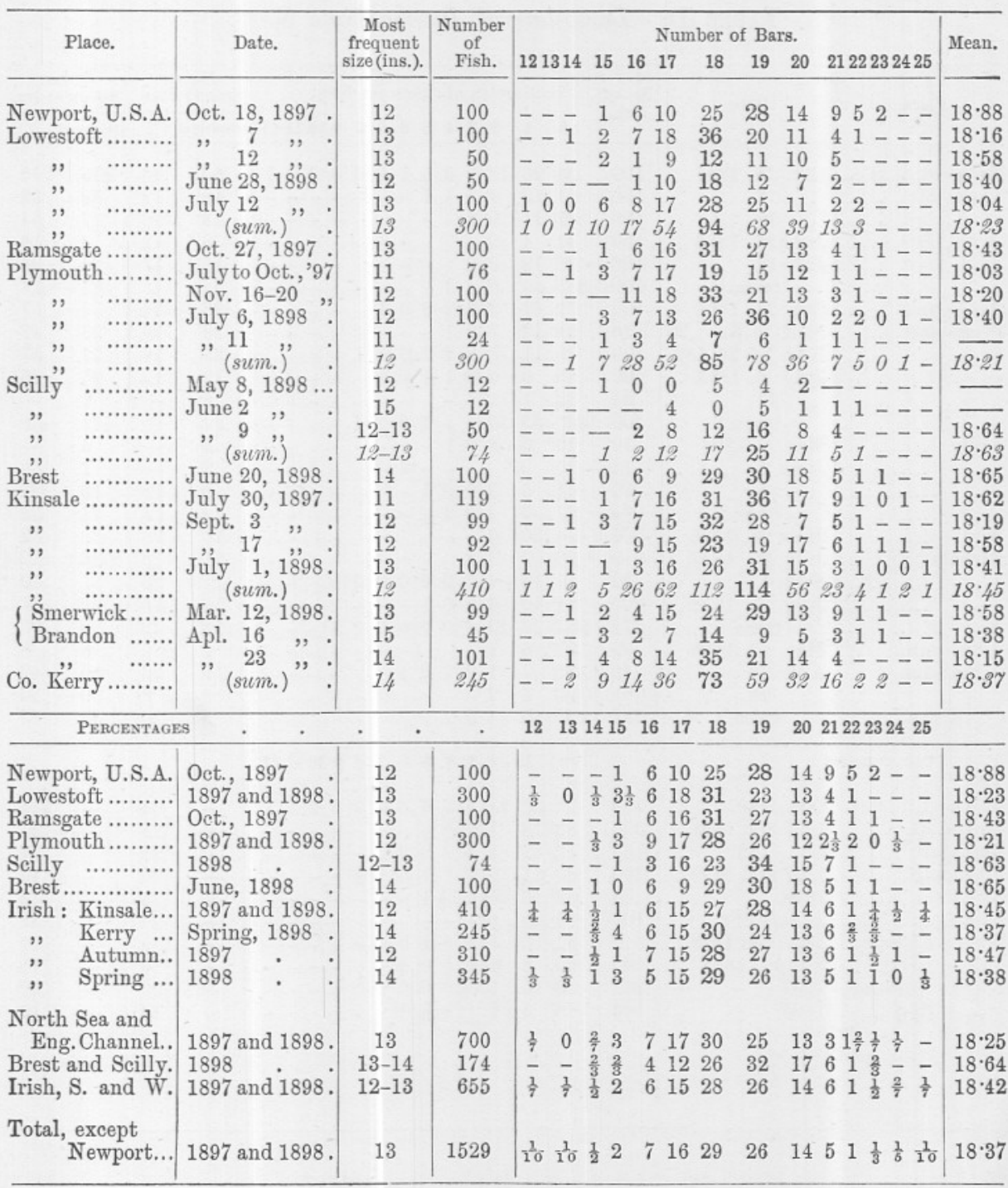


TABLE D. Dorso-lateral Intermediate Spots.

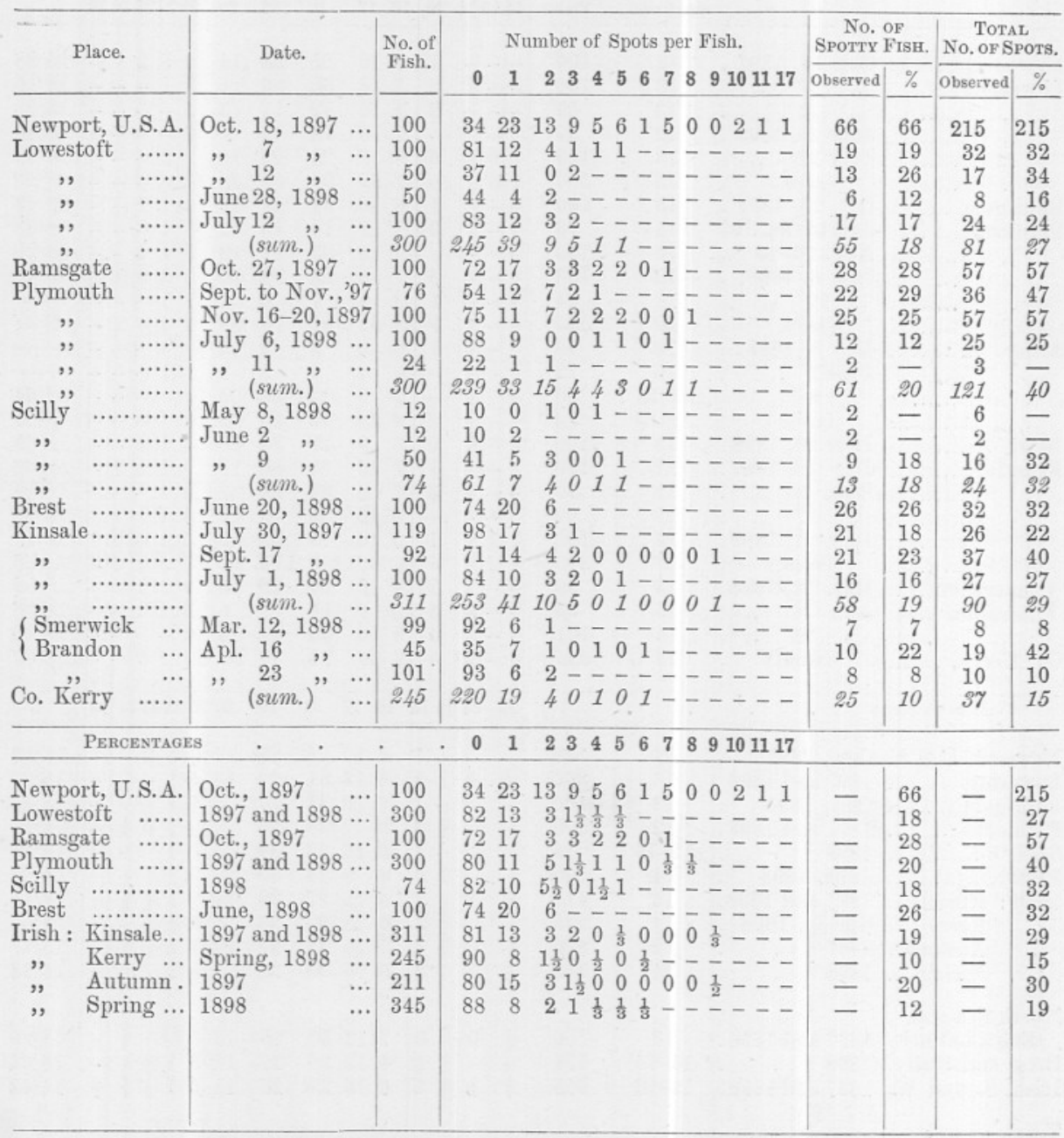


TABLe E. First Dorsal Fin and Proportion of Sexes.

\begin{tabular}{|c|c|c|c|c|c|c|c|c|c|c|c|}
\hline \multirow{2}{*}{ Place. } & \multirow{2}{*}{ Date. } & \multirow{2}{*}{$\begin{array}{c}\text { Most } \\
\text { frequent } \\
\text { size (ins.). }\end{array}$} & \multirow{2}{*}{$\begin{array}{c}\text { Number } \\
\text { of } \\
\text { Fish. }\end{array}$} & \multicolumn{2}{|c|}{ Sex. } & \multicolumn{5}{|c|}{ Number of Fin-rays. } & \multirow{2}{*}{ Mean. } \\
\hline & & & & $\sigma$ & q & 910 & 11 & 12 & 13 & 141516 & \\
\hline port, U.S.A & Oct. $18,1897 \ldots$ & 12 & 100 & 55 & 45 & -1 & 24 & 51 & 20 & $4--$ & $12 \cdot 02$ \\
\hline estoft .. & , $7, \quad, \quad \ldots$ & 1 & & - & - & -2 & 24 & 47 & 21 & $6--$ & 12.05 \\
\hline , . & $\begin{array}{llll} & 12 & 12 & \ldots\end{array}$ & $1:$ & 50 & $15:$ & $10(?)$ & -2 & 13 & 23 & 12 & --- & $11 \cdot 90$ \\
\hline , & June $28,1898 \ldots$ & 12 & 50 & 21 & 29 & -- & 11 & 20 & 16 & $3--$ & $12 \cdot 22$ \\
\hline$"$ & July $12,, \quad \ldots$ & 13 & 100 & 39 & 61 & -1 & 15 & 49 & 30 & $5--$ & 223 \\
\hline ," & (sum.) & 1. & $S$ & $75:$ & $100(?)$ & -5 & 631 & 189 & 79. & $14--$ & $2 \cdot 11$ \\
\hline Ramsgate ... & t. $27,1897 \ldots$ & 1 & 100 & 55 & 45 & -4 & 22 & 44 & 26 & $4--$ & $2 \cdot 04$ \\
\hline Plymouth ... & July to Oet.,'97. & 11 & 76 & - & - & -1 & 15 & 40 & 17 & $3--$ & 12.08 \\
\hline , & Nov. 16-20 & 12 & 100 & 41 & 59 & -4 & 14 & 51 & 26 & $41-$ & $12 \cdot 15$ \\
\hline & July $6,1898 \quad \ldots$ & 1 & 1 & 42 & 5 & -3 & 18 & 45 & 21 & $121-$ & $12 \cdot 24$ \\
\hline " &, $11 \quad$, & 1 & 24 & 10 & 14 & -- & 2 & 14 & 6 & $11-$ & \\
\hline & (sum.) & 12 & 300 & 93: & $181(?)$ & -8 & 49 & 150 & 70 & $203-$ & $12 \cdot 18$ \\
\hline 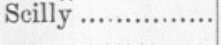 & May $8,1898 \ldots$ & 1 & 2 & 6 & 6 & -- & 1 & 5 & 6 & --- & 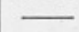 \\
\hline c. & June 2 , & 1 & 12 & 3 & 9 & -- & 1 & 5 & 3 & $3--$ & \\
\hline , & " 9 " & 12 & 50 & 21 & 29 & -1 & 8 & 15 & 20 & $42-$ & $2 \cdot 48$ \\
\hline$t$ & June $20,1898 \ldots$ & 14 & 100 & 30 & 44 & $\begin{array}{l}-1 \\
-3\end{array}$ & $\begin{array}{l}10 \\
22\end{array}$ & 25 & $\begin{array}{l}29 \\
29\end{array}$ & 7 & 50 \\
\hline Kinsale & July $30,1897 \ldots$ & 1 & 119 & - & - & -3 & 28 & 67 & $\begin{array}{l}22 \\
19\end{array}$ & $2--$ & $\begin{array}{l}2.00 \\
1.91\end{array}$ \\
\hline,$\quad \ldots$ & Sept. $3 \quad, \quad \ldots$ & 12 & 99 & - & - & 15 & 34 & 43 & 14 & $2--$ & $11 \cdot 65$ \\
\hline , & 17 & 12 & 92 & - & - & 10 & 18 & 51 & 22 & $-\ldots$ & $12 \cdot 01$ \\
\hline ", & y 1,18 & 13 & 100 & 44 & 56 & -1 & 20 & 50 & 23 & $6--$ & $12 \cdot 13$ \\
\hline ;' & (sum.) & 12 & 410 & - & - & 29 & 100 & 211 & 78 & $10--$ & 11.94 \\
\hline Smerwick ... & Mar. $12,1898 \ldots$ & 18 & 99 & 63 & 36 & -4 & 18 & 37 & 33 & $7--$ & $12 \cdot 21$ \\
\hline Brandon & Apl. $16 \quad, \quad \ldots$ & $1:$ & 45 & 20 & 25 & -1 & 19 & 14 & 9 & $11-$ & $11 \cdot 84$ \\
\hline Co. Kerry ........... & $, \quad \underset{\left(\text { sum. }_{.}\right)}{23}, \quad \cdots$ & $\begin{array}{l}14 \\
14\end{array}$ & $\begin{array}{l}101 \\
245\end{array}$ & $\begin{array}{r}43 \\
126\end{array}$ & $\begin{array}{r}58 \\
119\end{array}$ & $\begin{array}{l}-2 \\
-7\end{array}$ & $\begin{array}{l}18 \\
55\end{array}$ & $\begin{array}{l}48 \\
99\end{array}$ & $\begin{array}{l}31 \\
73\end{array}$ & $\begin{array}{lll}1 & 0 & 1 \\
9 & 1 & 1\end{array}$ & $\begin{array}{l}12 \cdot 15 \\
12 \cdot 12\end{array}$ \\
\hline Percentages & . & - & . & & . & 10 & 11 & 12 & 13 & 141516 & \\
\hline Newport, U.S.A.. & Oct. 18 & 12 & & 55 & $4:$ & -1 & 24 & 51 & 20 & $4--$ & $12 \cdot 02$ \\
\hline toft ... & 1 & 1 & & $4:$ & & -2 & 21 & 46 & 26 & & $2 \cdot 11$ \\
\hline isgate. & Oct., 1897 & 1 & & 55 & $4:$ & -4 & 22 & 44 & 26 & $4--$ & $12 \cdot($ \\
\hline mouth. & 1897 and $1898 \ldots$ & & 30 & $42:$ & 58 & -3 & 16 & 50 & 23 & $71-$ & $12 \cdot$ \\
\hline 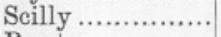 & 18 & $12-$ & 7 & $41:$ & 5 & -1 & 14 & 34 & 39 & $93-$ & $12:$ \\
\hline & $\mathrm{J}$ & 1 & & & & -3 & 22 & 50 & 22 & $3--$ & $12 \cdot 00$ \\
\hline ale. & $8 \ldots$ & 1 & & 44 & (?) & $\frac{1}{2} 2$ & 24 & 52 & 19 & $2 \frac{1}{2}--$ & $11 \cdot 9$ \\
\hline $\mathrm{K}$ & ng, $1898 \quad \ldots$ & 1 & 2 & 51 & 49 & -3 & $22 \frac{1}{3}$ & 40 & 30 & 4 & $12 \cdot 1$ \\
\hline Irish: $A u$ & & & & & & 12 & 26 & 52 & 18 & $1-$ & $11 \cdot 8$ \\
\hline " Spring & & 14 & 34 & 49 & 51 & -2 & 22 & 43 & 28 & $4 \frac{1}{2} \frac{1}{2}$ & $12 \cdot 1$ \\
\hline
\end{tabular}


TABLE F, First Dorsal Fin.

Distribution of Finray Numbers according to Sex and Size.

\begin{tabular}{|c|c|c|c|c|c|c|c|c|c|c|c|c|c|c|c|c|c|}
\hline \multirow[b]{2}{*}{ Place. } & \multirow{2}{*}{$\begin{array}{c}\text { Size } \\
\text { (ins.). }\end{array}$} & \multicolumn{7}{|c|}{ MALES. $ð$} & \multicolumn{9}{|c|}{ FEMALES. $\subsetneq$} \\
\hline & & $\begin{array}{l}\text { Number } \\
\text { of fish. }\end{array}$ & $\begin{array}{l}\text { Numb } \\
1011\end{array}$ & ber 0 & & & & Mean. & $\begin{array}{l}\text { Number } \\
\text { of fish. }\end{array}$ & & Numl & & $\begin{array}{l}\text { of } \mathrm{Fi} \\
131\end{array}$ & $\begin{array}{l}\text { Finra } \\
14.1\end{array}$ & $\begin{array}{l}\text { ays. } \\
15\end{array}$ & & Mean. \\
\hline 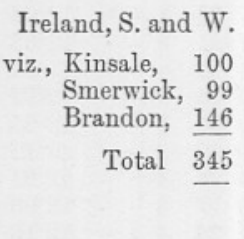 & \begin{tabular}{|l}
$11+$ \\
$12+$ \\
$13+$ \\
$14+$ \\
$15+$ \\
$16+$ \\
$17+$ \\
Total
\end{tabular} & $\begin{array}{c}2 \\
25 \\
52 \\
55 \\
30 \\
6 \\
\frac{170}{170}\end{array}$ & $\begin{array}{l}-\overline{5} \\
-5 \\
-8 \\
113 \\
110 \\
-2 \\
-\overline{2} \\
238\end{array}$ & $\begin{array}{c}- \\
9 \\
23 \\
25 \\
10 \\
2 \\
- \\
69\end{array}$ & $\begin{array}{c}1 \\
8 \\
19 \\
15 \\
9 \\
2 \\
- \\
54\end{array}$ & $\begin{array}{l}1 \\
3 \\
2 \\
1 \\
- \\
-\end{array}$ & $\begin{array}{l}- \\
\overline{-} \\
\overline{-} \\
\overline{-} \\
\overline{-}\end{array}$ & $\begin{array}{c}13 \cdot 50 \\
12 \cdot 24 \\
12 \cdot 29 \\
12 \cdot 04 \\
11 \cdot 90 \\
12 \cdot 00 \\
-12 \cdot 15\end{array}$ & $\begin{array}{c}3 \\
23 \\
36 \\
47 \\
44 \\
21 \\
1 \\
175\end{array}$ & $\begin{array}{l}\overline{2} \\
\overline{1} \\
2 \\
1 \\
\overline{6}\end{array}$ & $\begin{array}{c}- \\
3 \\
7 \\
9 \\
12 \\
5 \\
1 \\
37\end{array}$ & $\begin{array}{c}3 \\
6 \\
14 \\
29 \\
18 \\
10 \\
- \\
80\end{array}$ & $\begin{array}{c}- \\
9 \\
12 \\
6 \\
12 \\
3 \\
- \\
42\end{array}$ & $\begin{array}{l}\overline{3} \\
3 \\
1 \\
\overline{1} \\
\overline{8}\end{array}$ & $\begin{array}{l}\overline{-} \\
\overline{0} \\
\overline{1} \\
\overline{1}\end{array}$ & $\begin{array}{l}- \\
\overline{1} \\
\overline{1} \\
\overline{-} \\
\overline{1}\end{array}$ & $\begin{array}{l}12 \cdot 00 \\
12 \cdot 35 \\
12 \cdot 31 \\
12 \cdot 02 \\
11 \cdot 91 \\
12 \cdot 05 \\
11 \cdot 00 \\
12 \cdot 09\end{array}$ \\
\hline $\begin{array}{l}\text { English Channel } \\
\text { and North Sea. } \\
\text { viz., Plymouth, } 224 \\
\text { Ramsgate, } 100 \\
\text { Lowestoft, } \underline{175} \\
\text { Total }\end{array}$ & $\begin{array}{c}10+ \\
11+ \\
12+ \\
13+ \\
14+ \\
15+ \\
16+ \\
17+ \\
\text { Total }\end{array}$ & $\begin{array}{c}1 \\
31 \\
79 \\
79 \\
26 \\
6 \\
1 \\
223\end{array}$ & $\begin{array}{lc}\overline{2} & \overline{7} \\
- & 14 \\
2 & 15 \\
1 & 2 \\
- & 2 \\
- & - \\
\overline{5} & - \\
5\end{array}$ & $\begin{array}{l}\overline{17} \\
31 \\
37 \\
16 \\
3 \\
- \\
\overline{104}\end{array}$ & $\begin{array}{c}1 \\
4 \\
28 \\
21 \\
6 \\
1 \\
\overline{1} \\
62\end{array}$ & $\begin{array}{l}\overline{1} \\
5 \\
4\end{array}$ & $\begin{array}{l}- \\
\overline{1} \\
- \\
- \\
- \\
- \\
\overline{1}\end{array}$ & $\begin{array}{c}13 \cdot 00 \\
11 \cdot 84 \\
12 \cdot 34 \\
12 \cdot 13 \\
12 \cdot 15 \\
11 \cdot 83 \\
- \\
13 \cdot 00 \\
12 \cdot 17\end{array}$ & $\begin{array}{c}2 \\
34 \\
104 \\
86 \\
42 \\
6 \\
1 \\
1 \\
276\end{array}$ & $\begin{array}{l}\overline{1} \\
\overline{2} \\
3 \\
1 \\
1 \\
\overline{8}\end{array}$ & $\begin{array}{c}- \\
6 \\
18 \\
18 \\
8 \\
0 \\
- \\
- \\
501\end{array}$ & $\begin{array}{c}- \\
15 \\
50 \\
42 \\
19 \\
2 \\
- \\
- \\
128\end{array}$ & $\begin{array}{l}2 \\
7 \\
24 \\
22 \\
11 \\
3 \\
\overline{1} \\
70\end{array}$ & $\begin{array}{c}\overline{4} \\
11 \\
2 \\
1 \\
- \\
- \\
\overline{18}\end{array}$ & $\begin{array}{l}\overline{1} \\
1 \\
\overline{-} \\
\overline{-} \\
\overline{-} \\
\overline{2}\end{array}$ & $\begin{array}{l}- \\
- \\
- \\
- \\
- \\
- \\
- \\
-\end{array}$ & $\begin{array}{l}13 \cdot 00 \\
12 \cdot 29 \\
12 \cdot 30 \\
12 \cdot 05 \\
11 \cdot 98 \\
12 \cdot 17 \\
10 \cdot 00 \\
13 \cdot 00 \\
1217\end{array}$ \\
\hline Percentages. & $\cdots$ & б & 1011 & 12 & 13 & 1 & 15 & $\cdots$ & q & 101 & 11 & 1 & 131 & 141 & 15 & 16 & $\cdots$ \\
\hline Ireland, S. and W. & $\begin{array}{l}11+ \\
12+ \\
13+ \\
14+ \\
15+ \\
16+ \\
17+ \\
\text { Total }\end{array}$ & $\begin{array}{l}2 \\
25 \\
52 \\
55 \\
30 \\
\frac{6}{170}\end{array}$ & $\begin{array}{l}-\overline{-} \\
-20 \\
-15 \\
224 \\
333 \\
-33 \\
\overline{1}-\overline{22}\end{array}$ & $\begin{array}{l}3 \overline{6} \\
44 \\
45 \\
34 \\
34 \\
\overline{41}\end{array}$ & $\begin{array}{l}50 \\
32 \\
37 \\
27 \\
30 \\
33 \\
- \\
32\end{array}$ & $\begin{array}{l}50 \\
12 \\
4 \\
2 \\
-\end{array}$ & $\begin{array}{l}- \\
\overline{-} \\
\overline{-} \\
\overline{-} \\
-\end{array}$ & $\begin{array}{c}13 \cdot 50 \\
12 \cdot 24 \\
12 \cdot 29 \\
12 \cdot 04 \\
11 \cdot 90 \\
1200 \\
-\overline{12 \cdot 15}\end{array}$ & $\begin{array}{c}3 \\
23 \\
36 \\
47 \\
44 \\
21 \\
1 \\
175\end{array}$ & $\begin{array}{l}\overline{9} \\
\overline{9} \\
2 \\
5 \\
5 \\
\overline{5} \\
-1\end{array}$ & $\begin{array}{l}-1 \\
13 \\
20 \\
19 \\
27 \\
24 \\
100 \\
21\end{array}$ & $\begin{array}{l}100 \\
26 \\
39 \\
62 \\
41 \\
48 \\
- \\
46\end{array}$ & $\begin{array}{l}-\overline{39} \\
33 \\
13 \\
27 \\
14 \\
- \\
24\end{array}$ & $\begin{array}{l}\overline{13} \\
8 \\
2 \\
\overline{5} \\
\overline{5}\end{array}$ & $\begin{array}{l}\overline{-} \\
\overline{0} \\
\overline{4} \\
\overline{4}\end{array}$ & $\begin{array}{l}- \\
\overline{-} \\
\overline{2} \\
\overline{-} \\
\overline{-} \\
\overline{1}\end{array}$ & $\begin{array}{l}12 \cdot 00 \\
12 \cdot 35 \\
12 \cdot 31 \\
12 \cdot 02 \\
11 \cdot 91 \\
12 \cdot 05 \\
11 \cdot 00 \\
12 \cdot 09\end{array}$ \\
\hline $\begin{array}{l}\text { English Channel } \\
\text { and North Sea. }\end{array}$ & $\begin{array}{l}10+ \\
11+ \\
12+ \\
13+ \\
14+ \\
15+ \\
16+ \\
17+ \\
\text { Total }\end{array}$ & $\begin{array}{c}1 \\
31 \\
79 \\
79 \\
26 \\
6 \\
1 \\
223\end{array}$ & 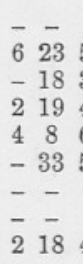 & $\begin{array}{l}-1 \\
55 \\
39 \\
47 \\
61 \\
50 \\
- \\
-1 \\
47\end{array}$ & $\begin{array}{l}100 \\
13 \\
36 \\
27 \\
23 \\
17 \\
1 \\
100 \\
28\end{array}$ & $\begin{array}{l}- \\
3 \\
6 \\
5 \\
4\end{array}$ & $\begin{array}{l}\overline{-} \\
\overline{1} \\
- \\
- \\
- \\
- \\
\overline{(1}\end{array}$ & $\begin{array}{c}13 \cdot 00 \\
11 \cdot 84 \\
12 \cdot 34 \\
12 \cdot 13 \\
12 \cdot 15 \\
11 \cdot 83 \\
- \\
13 \cdot 00 \\
12 \cdot 17\end{array}$ & $\begin{array}{c}2 \\
34 \\
104 \\
86 \\
42 \\
6 \\
1 \\
1 \\
276\end{array}$ & $\begin{array}{c}\overline{3} \\
\overline{2} \\
2 \\
7 \\
17 \\
100 \\
\overline{3}\end{array}$ & $\begin{array}{c}- \\
18 \\
17 \\
21 \\
19 \\
0 \\
- \\
- \\
18\end{array}$ & $\begin{array}{l}-1 \\
44 \\
48 \\
49 \\
45 \\
33 \\
- \\
-1 \\
46\end{array}$ & $\begin{array}{l}100 \\
21 \\
23 \\
26 \\
26 \\
50 \\
- \\
100 \\
25\end{array}$ & $\begin{array}{l}- \\
12 \\
11 \\
2 \\
3 \\
- \\
- \\
\overline{7}\end{array}$ & $\begin{array}{l}\overline{2} \\
1 \\
\overline{-} \\
\overline{-} \\
\overline{1} \\
\overline{1}\end{array}$ & $\begin{array}{l}- \\
- \\
- \\
- \\
- \\
- \\
- \\
-\end{array}$ & $\begin{array}{l}13 \cdot 00 \\
12 \cdot 29 \\
12 \cdot 30 \\
1205 \\
11 \cdot 98 \\
12 \cdot 17 \\
10 \cdot 00 \\
13 \cdot 00 \\
12 \cdot 17\end{array}$ \\
\hline
\end{tabular}


Table G. Second Dorsal Fin.

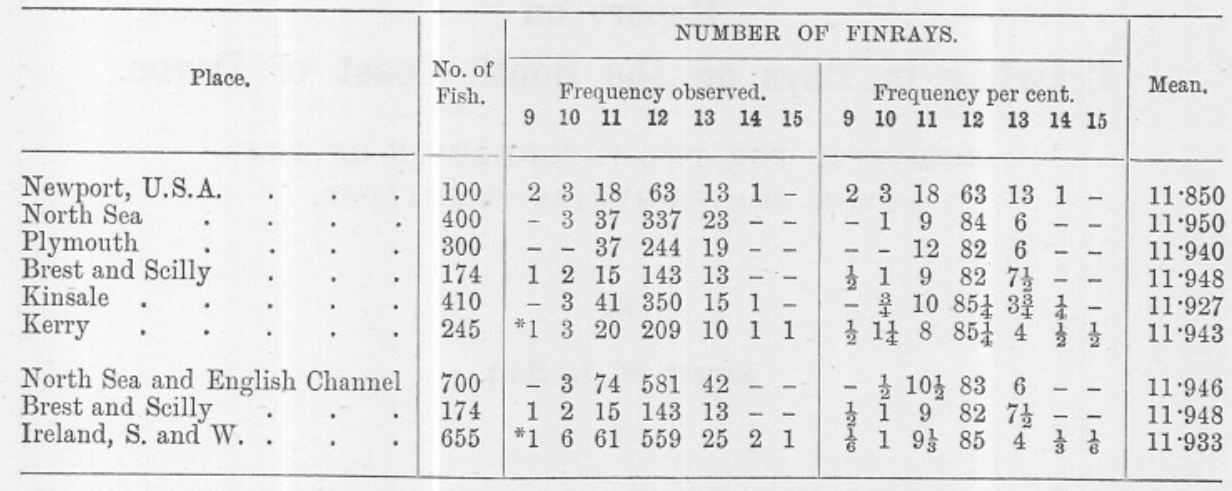

* Doubtful, owing to mutilation of fin. The number of rays may have been 10.

Table H. Dorsal Finlets.

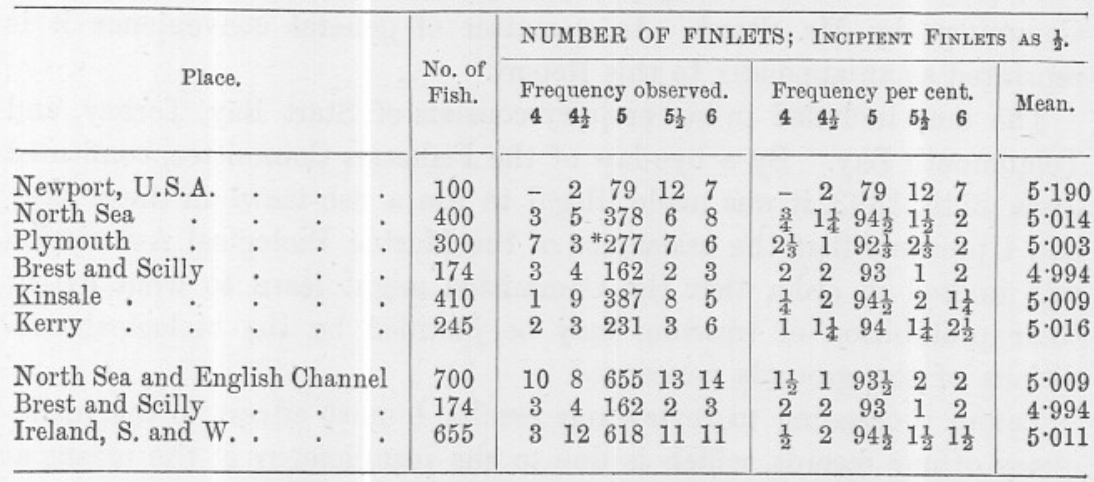

* One of these specimens actually possessed only 4 finlets, but the position of the 5th was so clearly indicated, that it was almost certainly lost by accident. 